\title{
Additive Manufacturing With Fibre-Reinforcement - Design Guidelines and Investigation Into the Influence of Infill Patterns
}

\begin{tabular}{|r|l|}
\hline Journal: & Rapid Prototyping Journal \\
\hline Manuscript ID & RPJ-09-2021-0223 \\
\hline Manuscript Type: & Original Article \\
\hline Keywords: & $\begin{array}{l}\text { Design for Additive Manufacturing, Process planning, Composite } \\
\text { materials, Toolpath Strategy }\end{array}$ \\
\hline
\end{tabular}

\section{SCHOLARONE \\ Manuscripts}




\section{Additive Manufacturing With Fibre-Reinforcement - Design Guidelines and Investigation Into the Influence of Infill Patterns}

\section{STRUCTURED ABSTRACT}

Purpose - Fibre-reinforced additive manufacturing (FRAM) with short and continuous fibres yields light and stiff parts and thus increasing industry acceptance. High material anisotropy and specific manufacturing constraints shift the focus towards design for AM (DfAM), particularly on toolpath strategies. Assessing the design-property-processing relations of infill patterns is fundamental to establishing design guidelines for FRAM.

Design/methodology/approach - Subject to the DfAM factors performance, economy and manufacturability, the efficacy of two conventional infill patterns (grid and concentric) was compared with two custom strategies derived from the medial axis transformation (MAT) and guided by the principal stresses (MPS). The recorded stiffness and strength, the required CPU and print time, and the degree of path undulation and effective fibre utilisation (minimum printable fibre length) associated with each pattern, served as assessment indices for different case studies. Moreover, the influence of material anisotropy was examined, and a stiffnessalignment index was introduced to predict a pattern's performance.

Findings - The highest stiffnesses and strengths were recorded for the MPS infill, emphasising the need for tailoring print paths rather than employing fixed patterns. In contrast to the grid infill, the concentric infill offered short print times and reasonable utilisation of continuous fibres. The MAT-based infill yielded an excellent compromise between the three DfAM factors and experimentally resulted in the best performance.

Originality - This constitutes the first comprehensive investigation into infill patterns under DfAM consideration for FRAM, facilitating design and processing choices.

Keywords: Design for Additive Manufacturing; Toolpath Strategy; Fibre-Reinforced Additive Manufacturing

Article Classification: Original Article

\section{Introduction}

Over the last decade, fibre-reinforced additive manufacturing (FRAM) has gained growing popularity in academia [1-8] and the industry [9-11], as it is deemed very promising for a range of industries such as aerospace, automotive and the biomedical sector $[1,12,13]$. Alongside, relevant software and hardware have emerged, consequently shifting the application and perception of polymers away from a pure means of prototyping towards an outright manufacturing method for the fabrication of strong, light and robust end-use parts. 


\subsection{Fibre-reinforced AM (FRAM)}

FRAM commonly encompasses the fused deposition modelling (FDM) of polymer-based filaments with short (S-FRAM) and continuous (C-FRAM) fibres as recently reviewed in $[1,14,15]$. Such layered manufacturing processes promote transversely isotropic properties (difference between in-plane and out-of-plane properties), following comparable rules found in composite laminate theories [16]. With FRAM, the fibre orientation thus clearly defines the favourable loading direction, which is the print direction (C-FRAM is comparable to, e.g. tailored fibre placement processes). The shear stress induced in the nozzle naturally aligns the (short) fibres along the printing direction [17-24], hence yielding enhanced properties in this direction. Various studies reported improved mechanical performance (Young's modulus and strength) of short [17,18,20,25-29] and continuous [4,30-51] fibre-reinforced parts compared to the unreinforced counterparts. A fivefold difference in Young's modulus between tension specimens printed in the longitudinal and transverse direction was, e.g. ascertained in [29]. The fibre volume fraction was identified as the most important factor affecting the performance [29]. Additionally, the critical fibre length, i.e. the fibre's effective length after extrusion, have been identified as decisive [19,26]. Multiple processing parameters [18,52-55] affect the performance, including inter- and intra-bead porosity [20,33,45,47,48,53,56,57]. For an overview of the mechanical properties and characteristics of FRAM, please refer to $[15,56,58-$ $60]$.

As the part performance is closely interconnected with both the manufacturability and the part and process design, the toolpath strategies, i.e. infill patterns, are becoming vital factors for the performance of AM parts. In [44], it was shown that the application of specific reinforcement design guidelines can significantly improve the strength, stiffness and toughness of parts manufactured with C-FRAM. Therefore, generic infills are no longer adequate, i.e. custom Slicer software for a tailored toolpath generation as well as updated design guidelines and rules will be essential in harnessing the capabilities of FRAM.

\subsection{DfAM and tool path generation with FRAM}

To unlock the full potential of AM, DfAM considerations are vital [61]. The slicing of CAD models is universal to all AM-processes and links design and manufacturing stages. Printing with continuous fibres poses unique manufacturing constraints, stemming from the necessary cutting process between individual paths (extrusion-free tool movement). Furthermore, the deposition of fibres is limited by the hardware-specific minimum length or minimum volume that can be reinforced (distance between the cut origin in the print head and the tip of the nozzle as shown in Fig. 5b)). Additionally, the smallest reinforceable feature size and the minimum fibre radius must be considered.

As reviewed in [62], various generic infill patterns including the raster path [63], zigzag path [64-67], contour path [68-70], spiral path [71-73], hybrid path [74,75], maze-like path [76] and continuous path [77,78] have been analysed for unreinforced applications. They are partly incorporated into today's Slicing software. Moreover, the economic side of DfAM, i.e. computationally inexpensive [79] and time-efficient patterns based on the 'Traveling Salesman' algorithm [80,81] or machine learning algorithms [82], have also been considered. 
Besides the fact that most of these toolpath strategies do not cater for the aforementioned manufacturing constraints of FRAM, aspects of performance will vary depending on the pattern and custom infill patterns will generally exhibit superior performances [83].

In the context of performance, the effect of different infill patterns on the mechanical properties has been investigated $[39,52,84]$. A higher flexural strength of continuous deposition path over zig-zag patterns was determined in [78], and maze-like patterns [76] were found to promote (quasi-) isotropic properties. The dependence of the detrimental in-plane gaps (porosity) on the infill strategy and parameters and geometrical features and complexity has been demonstrated in $[45,52,57]$. An appropriate approach for a pore-reducing infill strategy has been shown in [62,85-87].

Current challenges for DfAM with fibre-reinforced filaments revolve around understanding the impact and constraints of the material- [88] and process-induced orthotropy $[89,90]$ to inform better infill strategies, harnessing the potential of FRAM. Ideally, a concurrent optimisation of fibre trajectories and layout is required for this purpose, which is the subject of growing investigation [91-94] in, e.g. topology optimisation (TO). In this context, investigations revealed a link between mechanical efficiency and the expected stress direction using different patterns in the shell and infill region [91]. The contour paths derived from TO have also been used in [92] for a path planning solution for C-FRAM. This approach has been demonstrated to improve the part's strength. A similar steering method introduced in [93] led to a concurrent TO algorithm geared towards maximum stiffness and global control of the deposition paths [94].

From a practical standpoint, the superimposition of a given layout with print paths is more feasible to date as most design approaches consider isotropic materials. The above research direction on concurrent optimisation is still in its infancy. Moreover, independent of the design approach, the continuity of the paths $[33,95]$ constitutes another critical aspect in FRAM. As the number and location of discontinuities represent points of failure, i.e. weakspots [33,96], a single and continuous infill strategy [97] could be promising for C-FRAM, additionally easing processing. In [95], researchers presented a least-squares and continuity constraint approach and a pattern derived from streamlines, improving the compliance of SFRAM test samples. An increase in stiffness with infills aligning predominantly with the load trajectories was also exemplified experimentally using short- and continuous fibre filaments [96]. Inspiration for more advanced pathing strategies can also be drawn from TFP, including e.g. a stress-adapted tool path design [98] or equidistant and gap-free pathing methods derived from the fast marching method [99].

The number of slicing software for C-FRAM to date (see Table 1) is sparse and capabilities are still restrictive, which has also been indicated in $[39,96]$. Only a few control parameters and means to tailor the infill patterns are provided, often leading to fragmented and inefficient reinforcements with locally uneven or asymmetric distribution of fibre content. This leads to the requirement of time-consuming design adaptations. For complex freeform shapes, simple feature-recognition approaches (i.e. local hole reinforcement) or concentric infill patterns as often used with C-FRAM are not always expedient (arbitrary if not load-bearing). Moreover, if the external perimeters purely govern the paths, unreinforced artefacts, especially 
around smaller design features, may appear. Hence, an inside-out infill approach whereby the infill is guided concurrently by the internal and external representation of the structure (like in MAT and MPS) can potentially overcome these limitations. Generally, Slicing software should provide automated and adaptive solutions, accounting for the pertinent stress profile while avoiding excessive manual work and expertise in defining fibre paths.

Table 1: Tool path planning strategies and capabilities of commercial FRAM-specific slicer software.

\begin{tabular}{|c|c|c|}
\hline Slicer (Company) & Tool path planning features & Additional capabilities \\
\hline $\begin{array}{l}\text { Eiger (Markforged) } \\
{[100]}\end{array}$ & $\begin{array}{l}\text { - Concentric or Isotropic (stacking } \\
\text { sequence) infill }\end{array}$ & $\begin{array}{l}\text { - Feature-recognition (reinforced } \\
\text { inner and outer perimeters) }\end{array}$ \\
\hline $\begin{array}{l}\text { Fibrify }^{\mathrm{TM}} \\
(9 T L A B S)[101]\end{array}$ & $\begin{array}{l}\text { - Rectilinear, Concentric or Octogram } \\
\text { spiral infill } \\
\text { - Polygon-based fibre placement }\end{array}$ & $\begin{array}{l}\text { - Integration into FEA software } \\
\text { - Reinforced outer shells } \\
\text { - Corner fibre cutting corrections }\end{array}$ \\
\hline Aura (Anisoprint) [102] & $\begin{array}{l}\text { - Solid (stacking sequence) and grid-like } \\
\text { infills with custom rib and guide angles } \\
\text { - Mask-based fibre placement }\end{array}$ & $\begin{array}{l}\text { - Feature-recognition (reinforced } \\
\text { inner and outer perimeters) }\end{array}$ \\
\hline
\end{tabular}

\subsection{Scope and outline of the paper}

The outline of the paper is as follows. First, the underlying framework for generating the infill strategies (grid, concentric, MAT and MPS) is presented and subsequently, the DfAM factors (performance, economy and manufacturability) and associated assessment indices are introduced. Subsequently, in the last part of the methodology, the investigated case studies are detailed. Benchmark performances are established in the results section, and their sensitivity to fibre angle deviation is analysed, constituting comparative values for the four infill patterns. Next, DfAM indices are assessed for different case studies. Subsequently, the effect of material orthotropy is examined (S-FRAM vs C-FRAM). Finally, an experimental verification was conducted before the conclusions are summarised.

\section{$2 \quad$ Methodology}

\subsection{Generation of infill patterns}

In the context of functional prototyping or end-use fabrication, Slicers must work in conjunction with FEA software such that the infill pattern is tailored rather than generically selected. Fig. 1a) illustrates a framework for the design with FRAM that has been established (FRAMework) to create G-codes for the four infill strategies under investigation. Two typically used generic infill patterns in today's slicing software, namely grid (i.e. alternating $\pm 45^{\circ}$ or $0^{\circ} / 90^{\circ}$ print path orientation in consecutive layers) and concentric were compared to two novel infill patterns, termed MPS and MAT (see Fig. 1d/e)).

Geared towards an improved agreement between principal stress trajectories and tool path direction (i.e. fibre direction), it is hypothesised that the custom infills (MAT and MPS) improve the performance over conventional and fixed infill patterns. MAT is derived from the medial axis and is aimed at quickly and automatically providing a reinforcement pattern that mimics/maps the actual outline/geometry of the design. Hence, it is believed to be particularly 

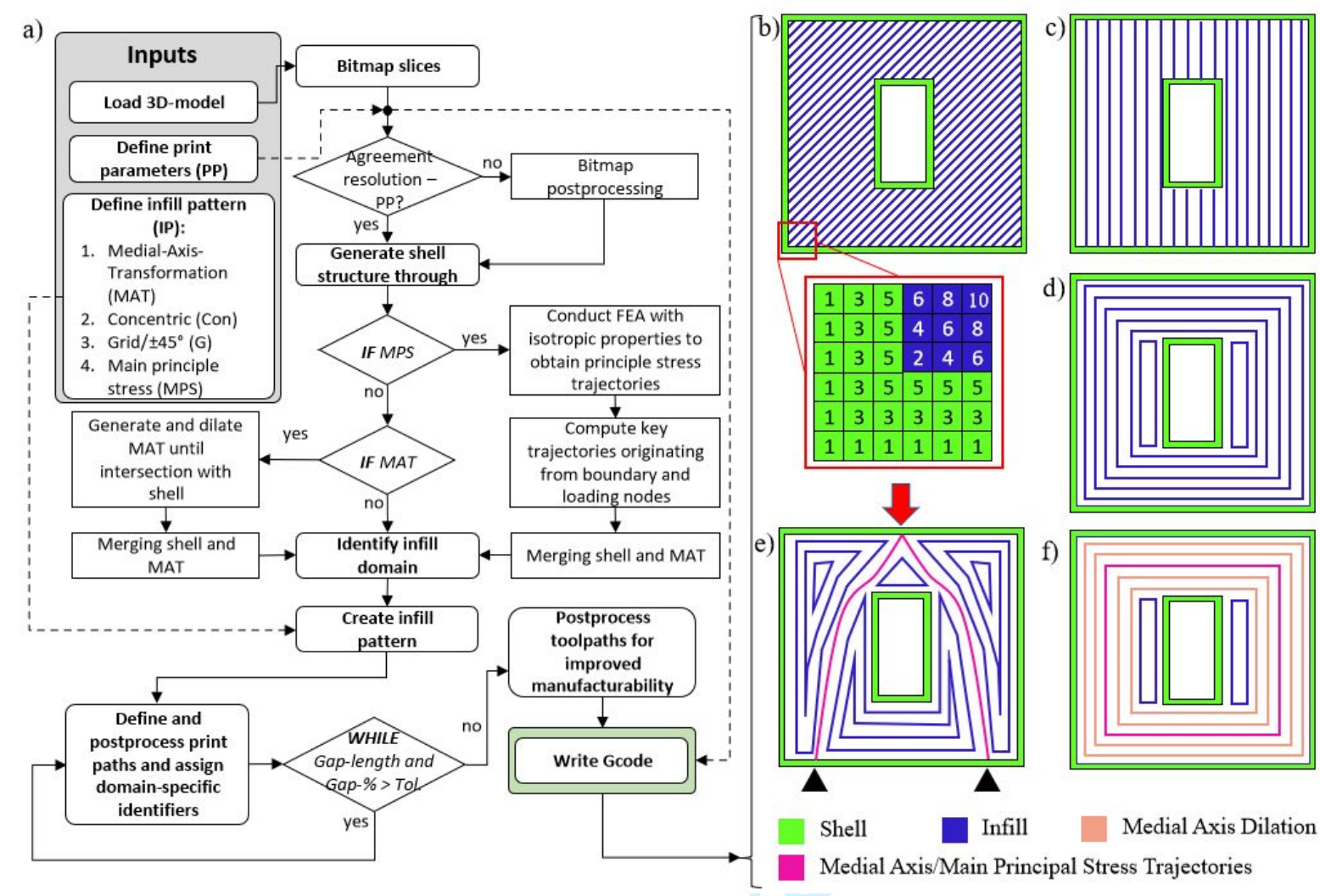

efficient for complex geometries with multiple boundaries. The MPS approach is geared towards a strategic placement of fibres to adapt to the specific loading scenario. Here, the optimum tool path strategy is derived from the principal stress trajectories, as obtained from a preceding FEA. The MAT infill is thus geometry-orientated, whereas stresses drive the MPS infill. Both strategies have emerged from the pursuit to best utilise continuous fibre printing by providing a higher degree of tailorability and purposefulness than the conventional infills used today.

Fig. 1: a) FRAMework - Flowchart highlighting the different steps for generating the G-code based on selected infill patterns and print parameters. b-f) Schematics of the b) $\pm 45^{\circ}$ and c) $0^{\circ} / 90^{\circ}$ grid infill, including the element numbering scheme. d) Concentric, e) MPS, and f) MAT infill strategies. Note that the concentric and MAT infill are identical due to simple geometry, and for the grid infill, only one layer is displayed.

As prefaced, this work focuses on a slice-by-slice 2D analysis of infill patterns for a specific load case. Single bitmap images were analysed; thus, the method encompasses the approach from a pixel environment to a continuous toolpath. MATLAB ${ }^{\circledR} 2018 b$ 's image processing toolbox was used to realise a code that would transform a bitmap image into the four infill patterns and finally into a G-code text file (as illustrated in Fig. 1)).

Initially, the bitmap image resolution (i.e. the pixel-density) must be adjusted to the print parameters and the physical size such that the bead-width of the printer (product of the nozzle diameter and layer height) produces a good inter-bead bonding. Subsequently, assignment of the domains i) shell, ii) medial axis or principal stress trajectory and iii) infill was conducted (in this order). For this purpose, a numbering scheme was introduced to identify individual print paths and their associated domains. Each was tagged with unique identifiers (compare close-up in Fig. 1b)). 


\subsubsection{Conventional vs custom infill patterns}

Across all four infill patterns, three concentric shell layers were defined first, clearly delimiting the outer-most perimeter and inner-most perimeters (holes) while providing a good surface finish. This is a common approach implemented in commercial slicing software. Erosion and dilation processes applied to the boundary elements of the bitmap slice defined the adjacent shell layers. An in-build MATLAB function (bwtraceboundary) was used to trace the boundary of those closed-loops, providing ordered pixel subscripts. For this purpose, a random start point was selected to avoid fibre discontinuities or resin-rich areas that would impair structural performance. The grid and concentric patterns were subsequently defined via Boolean operation and erosion/dilation steps. Here, MATLAB's in-build bwlabel function was utilised for assigning unique path identifiers.

The MAT-based infill follows the example of the author's previous work [39]; here, the skeletonisation was implemented with MATLAB's in-build bwmorph function, as demonstrated in Fig. 2. As the medial axis is established successively from the smallest to the largest index in the bitmap matrix, post-processing steps were required to clean redundant spurs/branches or ensure symmetry (e.g. symmetric slice). The branched medial axes were segmented so that they can later be printed individually. The next step consisted of the recursive dilation of the medial axis until the intersection with a shell layer (see Fig. 2c)). This yielded an infill pattern concentrically formed from the inside out with MAT-identifiers for each skeletal shell layer/toolpath. The remaining domains were finally filled with concentric toolpaths.
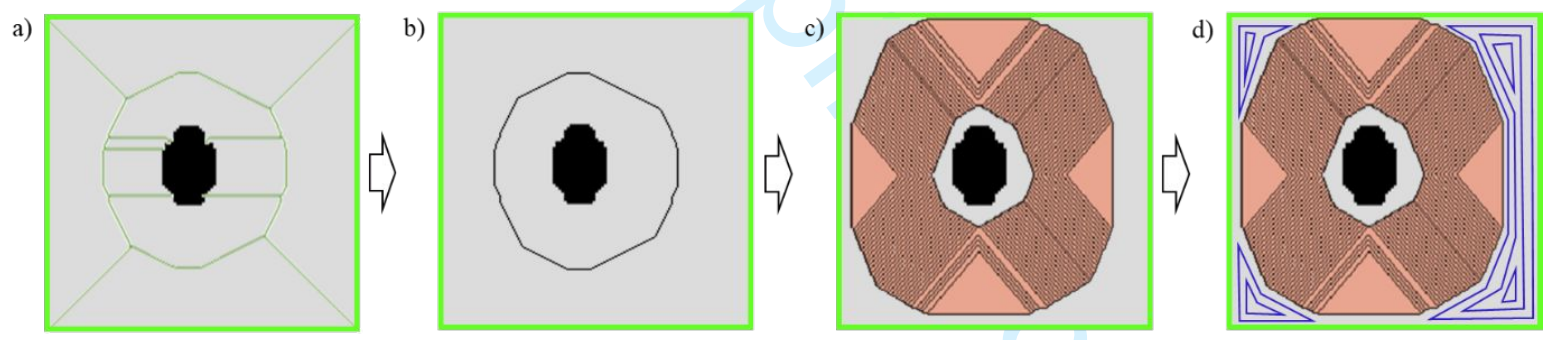

Fig. 2: Medial axis transformation a) before and b) after post-processing, exemplified by the simple cubic slice with a hole. c) Dilation of medial axis up to perimeter and d) infill of remaining space with the concentric pattern.

On the other hand, the MPS-paths follows an approach whereby the node at which the load or the boundary conditions are applied were used as starting points for establishing the 'main' principal stress paths using MATLAB's in-build streamline function (compare Fig. 1e)). MPS is used to establish literal guidelines used to fill the remaining domains with a concentric infill. Thus, it represents an approach for determining the dominant path, governing a simplified blueprint of the stress state. In cases where multiple nodes were constrained, a node at or close to the centre of this array was selected. Likewise, the starting node of the MPS was manually chosen for slices with multiple holes that manifested in various branched-out features. This ensured that emerging stand-alone paths occupy/encapsulate a large portion of the slice (comparable to the links between the branches of the medial axis). 


\subsubsection{Toolpath post-processing}

As shown in Fig. 3, a two-stage line simplification operation was conducted when transforming the pixelated toolpath into the G-code. This included: i) Reduction of straight lines to start- and end-points to reduce the G-code size and ii) mitigation of the staircasing effect in case of paths angled at $45^{\circ}$ to improve the path's smoothness and hence the manufacturability. Resultant isolated or 'empty' pixels (no connectivity in $3 \times 3$ vicinity) have been compensated for in the G-code with increased extrusion values. Likewise, these elements were assigned an equivalent average of fibre angle in the FEA based on the $3 \times 3$ neighbourhood (see Fig. 3e)). In all other elements, the principal material direction was aligning with the toolpath direction.

a)
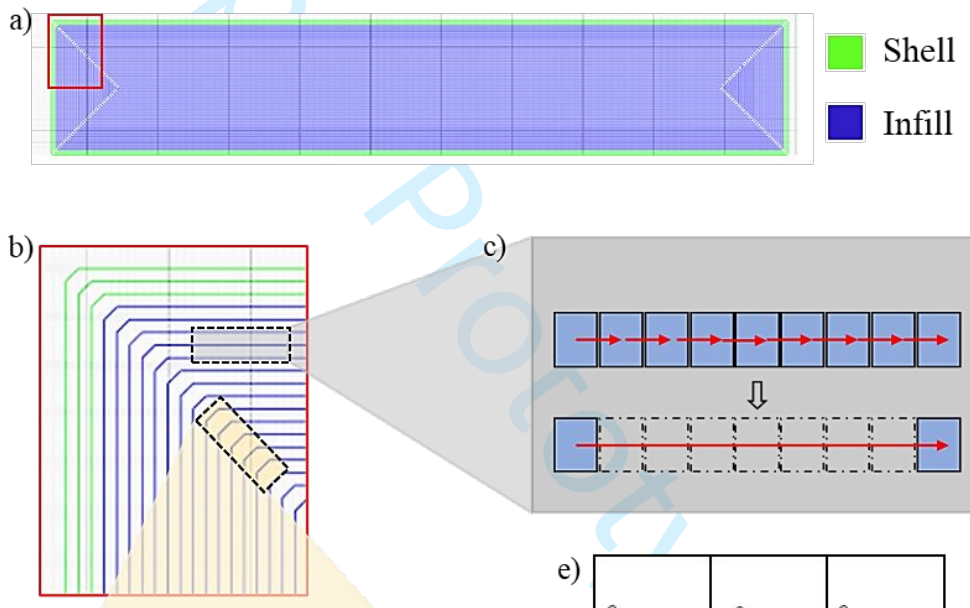

d)

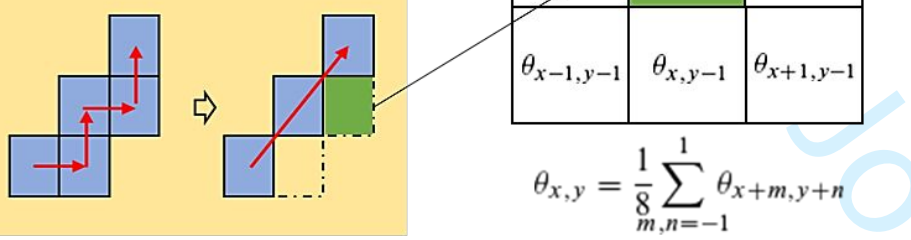

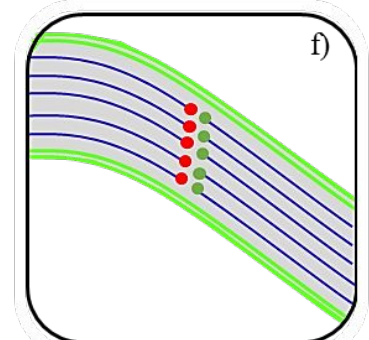
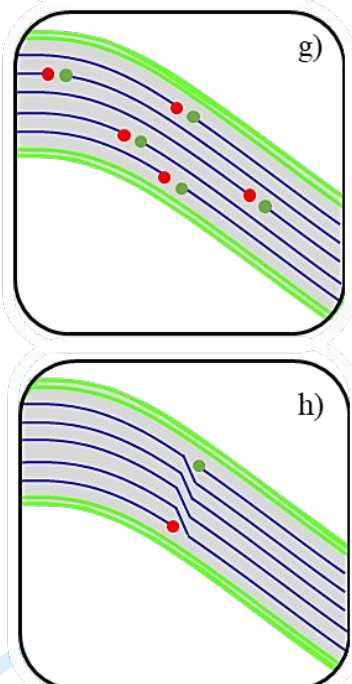

Fig. 3: a) Tension specimen with concentric infill and b) close-up showing the toolpaths. c/d) Visualisation of the line simplification for straight and staircased toolpaths, including e) the approach for determining the average fibre angle in pixel artefacts. f-h) Different implementations of toolpath start- and end-point implementations from worse to best: f) Locally fixed; g) randomised (used in this work) and h) continuous.

\subsection{DfAM factors and associated assessment indices}

Seven different assessment indices related to the three different DfAM factors: i) Economy, ii) Manufacturability and iii) Performance were chosen for comparing the characteristics of the different infill patterns, as summarised in Table 2. The numerical results of each DfAM index are analysed in spider plots to elucidate potential interdependencies and characteristic features. 
Table 2: Assessment matrix for analysing different DfAM factors.

\begin{tabular}{|c|c|c|c|c|}
\hline $\begin{array}{l}\text { DfAM } \\
\text { Factors }\end{array}$ & Assessment indices & Metric & Method & Software/Code \\
\hline \multirow{4}{*}{ 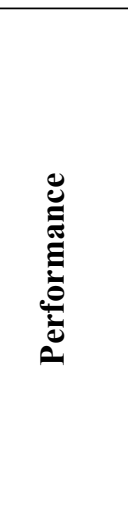 } & $\begin{array}{l}\text { Sum of elemental } \\
\text { strain energies }\end{array}$ & {$\left[\mathrm{Jm}^{-3}\right]$} & $\begin{array}{l}\text { - FEA with C3D8R elements } \\
\text { - Output variable: SENER }\end{array}$ & $\begin{array}{l}\text { Abaqus/In- } \\
\text { house }\end{array}$ \\
\hline & Maximum stress & {$[\mathrm{MPa}]$} & $\begin{array}{l}\text { - FEA with C3D8R elements } \\
\text { - Output variable: S11; S22; S33; S12; S23; } \\
\text { S13 }\end{array}$ & $\begin{array}{l}\text { Abaqus/In- } \\
\text { house }\end{array}$ \\
\hline & $\begin{array}{l}\text { Normalised } \\
\text { Stiffness- } \\
\text { Alignment Index PI }\end{array}$ & {$[\%]$} & $\begin{array}{l}\text { - FEA with C3D8R elements } \\
\text { - The direction of tool path vs Cauchy stress } \\
\text { tensor (Mohr's Circle) as normalised strain } \\
\text { energy score from } 0 \text { to } 1 \\
\text { - Elemental strain magnitude is factored in }\end{array}$ & $\begin{array}{l}\text { Abaqus/In- } \\
\text { house }\end{array}$ \\
\hline & $\begin{array}{l}\text { Material orthotropy } \\
\text { (S-/C-FRAM) }\end{array}$ & {$[/]$} & $\begin{array}{l}\text { - FEA with C3D8R elements } \\
\text { - Material properties (see Table 5) }\end{array}$ & n.a. \\
\hline \multirow{2}{*}{ 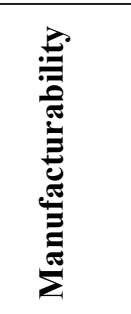 } & $\begin{array}{l}\text { Sinuosity Index } \\
\text { SI }\end{array}$ & {$[1, \infty]$} & $\begin{array}{l}\text { - Douglas-Peucker-Algorithm [103] } \\
\text { - Average of SI-scores obtained with the } \\
\text { tolerances taking the values: } 0.001 ; 0.8 ; 1 \\
\text { and } 1.2 \text {. }\end{array}$ & $\begin{array}{l}\text { MATLAB/Rec } \\
\text { ursive polyline } \\
\text { simplification } \\
\text { function }[104]\end{array}$ \\
\hline & $\begin{array}{l}\text { Tool path length }> \\
40 \mathrm{~mm}\end{array}$ & {$[\%]$} & $\begin{array}{l}\text { - The Euclidian distance of discretised } \\
\text { toolpaths }\end{array}$ & $\begin{array}{l}\text { Abaqus/In- } \\
\text { house }\end{array}$ \\
\hline \multirow{2}{*}{ 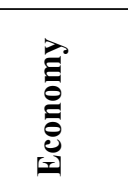 } & CPU time & [sec] & $\begin{array}{l}\text { - Time from reading the bitmap file to } \\
\text { writing a G-code }\end{array}$ & $\begin{array}{l}\text { MATLAB/tic- } \\
\text { toc function }\end{array}$ \\
\hline & Print time & {$[\mathrm{sec}]$} & $\begin{array}{l}\text { - Time for printing a single layer based on } \\
\text { print and travel speed }\end{array}$ & $\begin{array}{l}\text { MATLAB/in- } \\
\text { house }\end{array}$ \\
\hline
\end{tabular}

\# Note: This is an intrinsic material factor affecting the performance and was assessed separately.

Performance - The performance factor captures stiffness as the sum of strain energies (inverse of stiffness), the maximum stress. Moreover, the accordance of the tool paths with the principal stress trajectories was determined. This last parameter was termed the stiffnessalignment index and assesses the efficacy of the infills. It was established by conducting an FEA considering isotropic material properties, which yields the element-wise principal stress trajectories i.e. the ideal fibre-alignment (also used for MPS). Aligning the principal material properties in each element with the corresponding principal stress direction thus provided the optimal benchmark example, which was decoupled from any toolpath constraints. For this purpose, the fibre angle (i.e. the principle material orientation) in each element was rotated by $\theta$ in steps of $x$ such that

$$
x=\{5, r: r=10+10 \times n, n \in\{0,1, \ldots 8\}\}
$$

As the investigated case studies (see Table 3 ) are symmetric along the loading axis, the elements on the left and right were rotated clockwise or anti-clockwise and vice versa. Consequently, the strain energy and stress values for angle deviations from $-90^{\circ} \leq \theta \leq 90^{\circ}$ were obtained. The data was subsequently fitted $x$-1 order polynomial function $f(P I(\theta))$ and normalised by the lowest elemental strain energy $S E$ recorded for the optimal benchmark case.

$$
f(P I(\theta)) \text { with: } P I(\theta)=\frac{\sum_{i=1, \theta}^{N} \mathrm{SE}_{i, \theta}}{\min _{x \rightarrow n}\left(\mathrm{SE}_{\theta(x)}\right)} \text {. }
$$


Similarly, the change of the maximum local stress was plotted as a function of fibre angle deviation. Drawing the parallel to the density-based topology optimisation method [105], $P I(\theta)$ of an element was penalised by a factor of three based on its normalised elemental strain energy such that $P I$ yields the average performance given as

$$
P I=\frac{1}{N} \sum_{i=1}^{N} f\left(P I\left(\Delta \theta_{i}\right)\right) \times \mathrm{SE}_{i, n o r m}^{3}+1,
$$

with $\Delta \theta_{i}$ as the elemental fibre angle deviation between the toolpath and the principal stress direction (i.e. benchmark case). This ensures that the element-wise stress intensity is factored into the normalised performance index $P I(\theta)$, expressing a joint parameter between stiffness and alignment.

Another aspect affecting the performance-related indices are the material properties. The degree of material orthotropy, i.e. the ratio between the elastic constants $E_{11}$ to $E_{22}$, is significantly different between S-FRAM and C-FRAM (see Table 5). While this is an intrinsic material factor, it will be assessed separately from the remaining six indices.

Economy - With regards to economy, i.e. cost-efficiency, the computational expense for transforming the design to the G-code (i.e. CPU time) and the actual print time, which is a product of print/moving speed and distance between individual paths. The randomisations in path initiation and direction and the iterative nature of the code (compare Fig. 1) affect the final pattern and G-code. Thus, it must be noted that the presented codes are not optimised for a minimum print time. Consequently, CPU times for repeated runs will not be identical and thus not rigorously comparable; however, they will still be reported to reflect trends.

Manufacturability - The paths' smoothness (sinuosity index) and length (percentage paths greater than a certain threshold) were analysed. The latter is of importance for C-FRAM, as the fibres need to be cut, in which case the hardware-specific minimum printable fibre-length (distance between the location of cut and nozzle tip as shown in Fig. 5b)) must be considered (see Fig. 4).
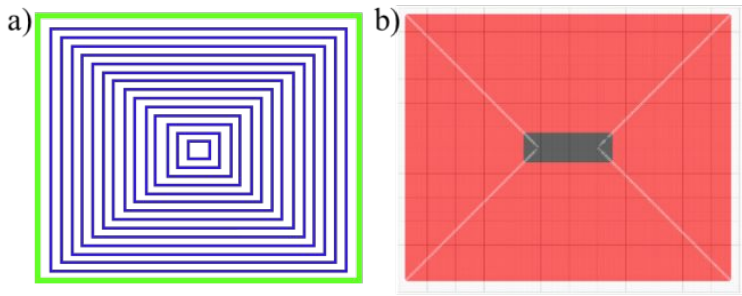

C-FRAM S-FRAM
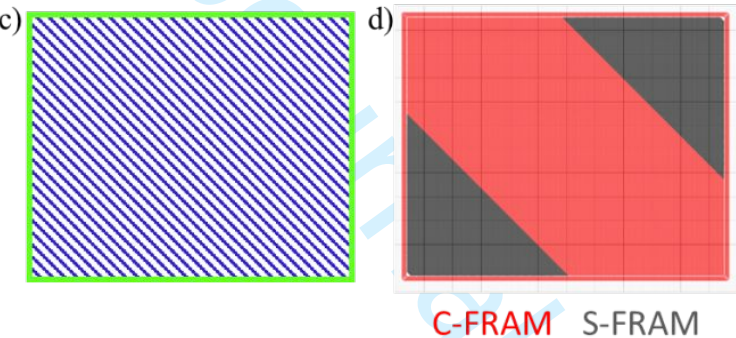

Fig. 4: a/c) Schematic illustration of a slice with a $\mathrm{a} / \mathrm{b}$ ) concentric and a c/d) grid infill (showing $45^{\circ}$ path angle) together with $\mathrm{b} / \mathrm{d}$ ) the corresponding C-FRAM and S-FRAM domains based on the minimum fibre length.

\subsection{Case studies and implementation}

The subjects of the investigation are three different case studies to elucidate how i) the loading scenario, ii) the geometry and iii) the material properties influence the DfAM-specific assessment indices. Firstly, the open-hole tension case- commonly used in the context of fibreplacement - following the ASTM standard D5766/D5766M [106], is analysed to highlight 
DfAM specific differences between different infill patterns. Secondly, a tension specimen with multiple open holes is presented to illustrate the influence of geometrical complexity. Thirdly, a topology optimised 3-point-bending beam example (TO-3PB) - similar to the test set-up described in ASTM D7264/D7264M - 15 [107] - is analysed both numerically and experimentally. It aims to highlight the effect of the degree of material anisotropy, the performance considering multi-material prints (combined S-FRAM and C-FRAM), and compare and verify the methodology, respectively. Test case III) is created using SIMP (Solid Isotropic Material with Penalisation) topology optimisation method as presented in [105]. Key metrics have been defined, which will be the focus in the assessment and discussion of the results.

Table 3: Test case matrix visualising and summarising the case study configuration under investigation.

\begin{tabular}{|c|c|c|c|}
\hline \multirow{2}{*}{ Case study } & \multirow{2}{*}{\multicolumn{2}{|c|}{\begin{tabular}{l|l}
$\frac{\text { 1) Single Open-Hole }}{\text { II) Multiple Open-Hole }}$ \\
Tension
\end{tabular}}} & \multirow{2}{*}{$\frac{\underline{\text { III) } \mathrm{TO}-3 \mathrm{~PB}}}{\text { Flexure }}$} \\
\hline & & & \\
\hline & $\hookrightarrow \begin{array}{c}L \\
\longleftarrow \quad 0.6 L\end{array}$ & $\longleftarrow \begin{array}{c}L \\
\\
\end{array}$ & \\
\hline & 0 & $\begin{array}{lll}0 & 0 \\
0 & 0 & 0 \\
\end{array}$ & \\
\hline Aspect ratio & $5.6: 1$ & 8 & $1: 3.4$ \\
\hline Details & $\begin{array}{l}\text { - Hole radius: } 6 \mathrm{~mm} \\
\text { - Cut-out area: } 131 \mathrm{~mm}^{2} \\
\text { - Resultant load: } 1 \mathrm{~N}\end{array}$ & $\begin{array}{l}\text { - Hole radius: } 4 \mathrm{~mm} \\
\text { - Cut-out area: } 251 \mathrm{~mm}^{2} \\
\text { - Resultant load: } 1 \mathrm{~N}\end{array}$ & $\begin{array}{l}\text { - Volume fraction }=0.6 \\
\text { - Stepped point loads: } 0.5 \mathrm{~N} \& \\
1 \mathrm{~N}\end{array}$ \\
\hline Key metrics & $\begin{array}{l}\text { - DfAM baseline for case } \\
\text { II) } \\
\text { - Comparison to } \\
\text { benchmark } \\
\text { - Performance considering } \\
\text { multi-material prints (C- } \\
\text { FRAM vs S-FRAM) }\end{array}$ & $\begin{array}{l}\text { - Influence of higher } \\
\text { geometrical complexity } \\
\text { on DfAM in } \\
\text { comparison to I) }\end{array}$ & $\begin{array}{l}\text { - Influence of material } \\
\text { orthotropy on performance } \\
\text { - Comparison to benchmark } \\
\text { - Performance considering } \\
\text { multi-material prints (C- } \\
\text { FRAM vs S-FRAM) } \\
\text { - Experimental verification }\end{array}$ \\
\hline
\end{tabular}

Experimental details - The experimental investigation encompasses the TO-3PB test case (see Table 3). A custom FDM 3D printer based on the Creality CR-10 (see Fig. 5) was utilised for fabrication with the processing parameters as summarised in Table 4. It was upgraded by micro-stepper motors geared toward high-precision material deposition, which becomes particularly crucial for C-FRAM. A Duet3D [108] control-board, administering multiple motors, fans and ensuring compatibility with G-code files based on the Marlin syntax

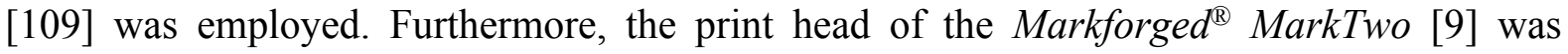
repurposed for this printer.

Table 4: 3D-printing manufacturing parameters.

\begin{tabular}{l|l|l|l|l|l}
\hline Print parameter & Value & Print parameter & Value & Print parameter & Value \\
\hline Feedstock material & Onyx $[9]$ & Filament diameter & $1.75 \mathrm{~mm}$ & Layer height & $0.2 \mathrm{~mm}$ \\
Nozzle temperature & $280^{\circ} \mathrm{C}$ & Build plate temp. & $70^{\circ} \mathrm{C}$ & Print/Moving speed & $8.3 / 91.6 \mathrm{~mm} / \mathrm{s}$ \\
\hline
\end{tabular}


Two samples for each infill pattern were printed, whereby only the $\pm 45^{\circ}$ variant was chosen as grid infill. The specimens were tested on a $10 \mathrm{kN}$ Instron machine with a 3PB fixture equipped with loading and support pins of $5 \mathrm{~mm}$ diameter (see Fig. $5 \mathrm{c}$ )). The displacement control was applied at $1 \mathrm{~mm} / \mathrm{min}$.
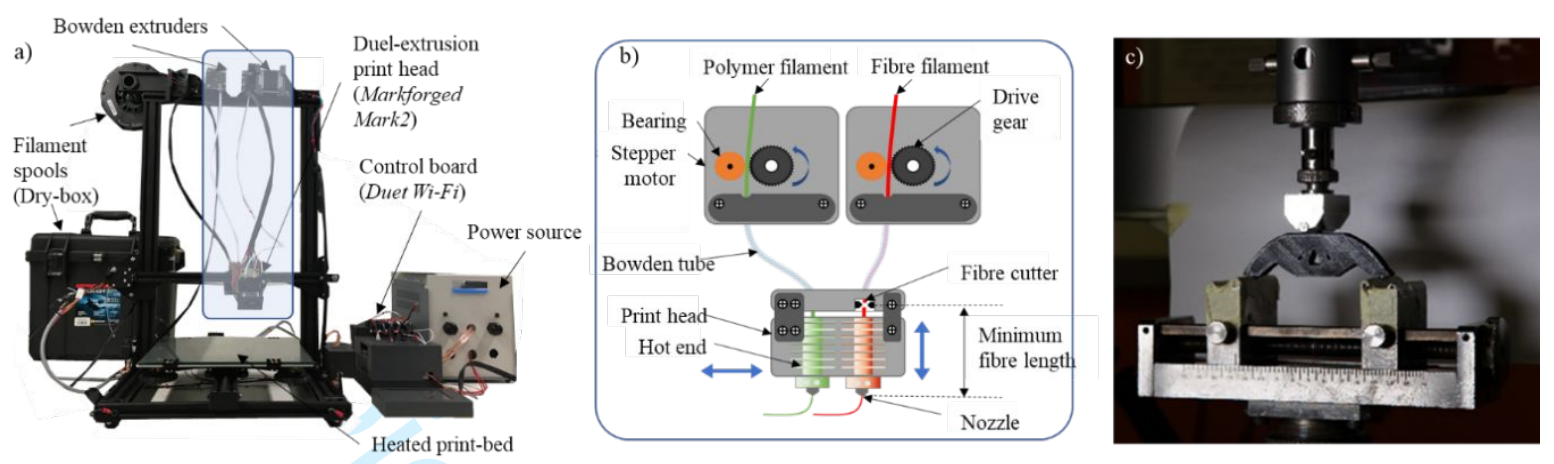

Fig. 5: a) Custom FDM printer for FRAM, equipped with a dual-extrusion head as schematically detailed in b). c) 3-Point-Bending test setup for the topology optimised flexure specimens.

Simulation details - All FEA simulations were conducted in Abaqus/CAE2018, using C3D8R elements, whereby the principal material direction $E_{11}$ was element-wise adjusted to fit the local toolpath direction. Both C-FRAM and S-FRAM properties were considered in the case studies, shedding light on the effect of the level of material orthotropy (ratio of the elastic Young's moduli $E_{11}$ to $E_{22}$ ) on the mechanical performance. While the majority of material properties of the short and continuous fibre-reinforced PA of Markforged Inc. have already been experimentally determined elsewhere [110,111], to the knowledge of the authors, data on the in-plane shear modulus $\mathrm{G}_{12}$ has yet to be determined. As the level of orthotropy is low for S-FRAM, the shear stiffness has been obtained assuming isotropic behaviour, i.e. $G_{12}=E_{11} /(2$ $\left.\times\left(1+v_{12}\right)\right)$.

Table 5: Material properties used for finite element analyses as obtained or approximated from experimental studies.

\begin{tabular}{l|c|c|c|c|c} 
Material & $\mathbf{E}_{\mathbf{1 1}}[\mathbf{G P a}]$ & $\mathbf{E}_{\mathbf{2 2}}$ [GPa] & $\mathbf{E}_{\mathbf{1 1}} \mathbf{\mathbf { E } _ { \mathbf { 2 2 } }}$ & $\mathbf{G}_{\mathbf{1 2}}[\mathbf{G P a}]$ & $\boldsymbol{v}_{\mathbf{1 2}}$ \\
\hline S-FRAM [110] & 1.9 & 1.1 & $1: 1.7$ & $0.7^{*}$ & 0.41 \\
C-FRAM [111] & 73.2 & 4.1 & $1: 17.9$ & 2.2 & 0.33 \\
\hline
\end{tabular}

*Note: Approximation, assuming isotropic material behaviour: $\mathrm{G}_{12}=\mathrm{E}_{11} /\left(2 \times\left(1+\mathrm{v}_{12}\right)\right)$.

\section{Results \& Discussion}

3.1 Performance as compared to the benchmark case

Case Study I) - Fig. 6a-f) showcase the infills for the open-hole case studies as developed according to the method discussed in paragraph 2.1. These were compared with the ideal benchmark case for which the principal material direction was aligned with the principal stresses rather than the local toolpath orientation (see Fig. 6g-j)). 

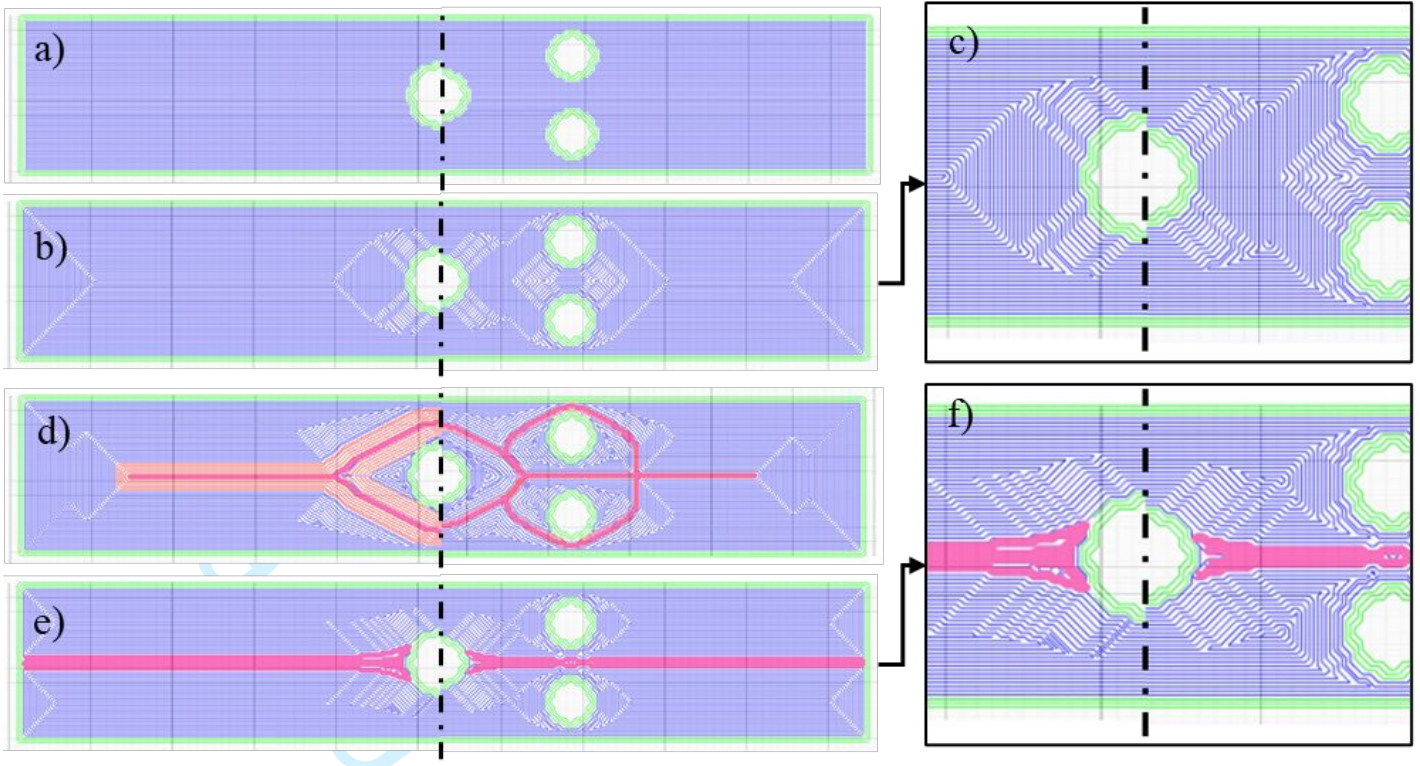

g)

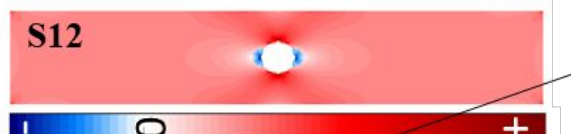

\section{S11}
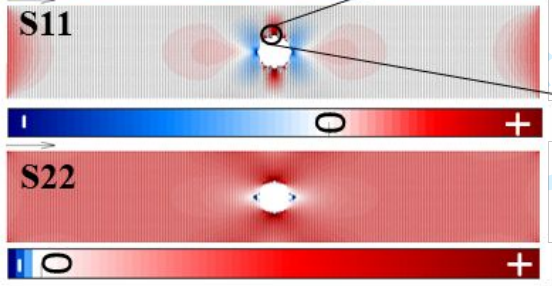

k) $1.2 \times 10^{-4}$

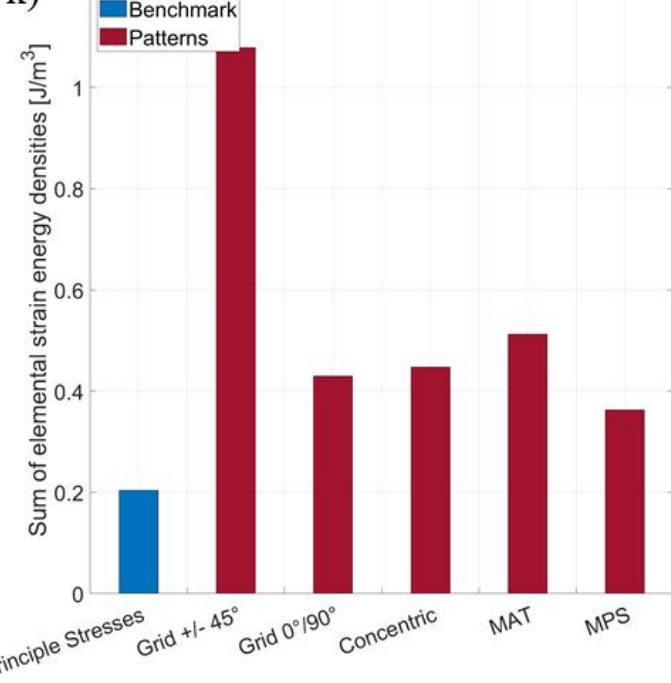

h)

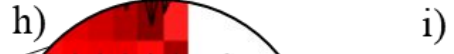

i)

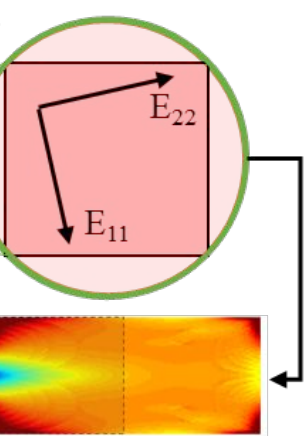

j)

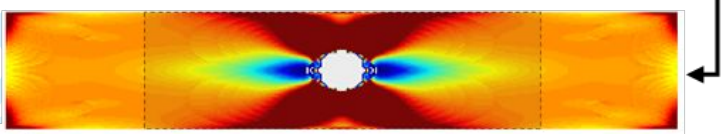

1) 0.06

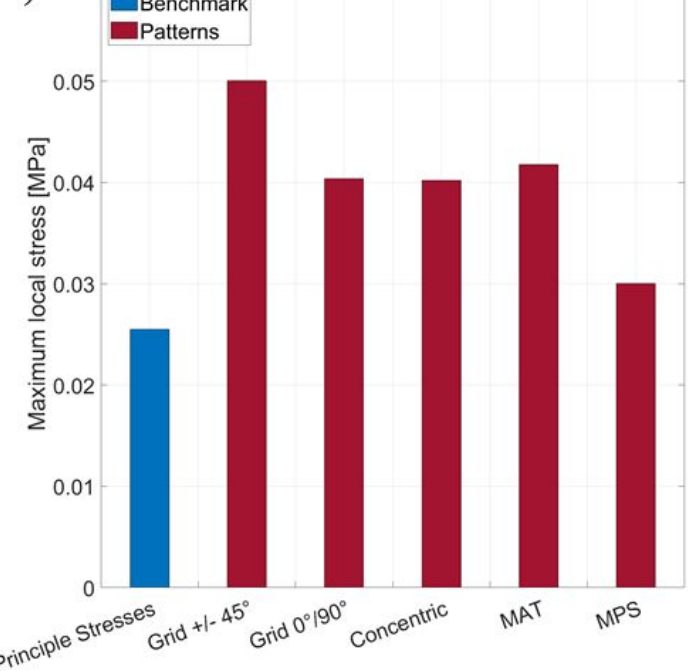

Fig. 6: Visualisation of the infill patterns of the a) grid infill $\left(0^{\circ} / 90^{\circ}\right.$ variant displayed $)$, b) the concentric, d) the MAT, and e) the MPS infill patterns for open-hole cases (split view). Close-ups of the c) concentric and $\mathrm{f}$ ) MPS strategies. g) In-plane stresses of the single open-hole case study, including h) a close-up of the principal stress trajectories and i) the corresponding alignment of the principal material orientation to obtain the $\mathrm{j}$ ) benchmark performance (showing strain energy distribution). k) Sum of strain energies and l) maximum stress between the benchmark sample and the different infill.

As summarised in Fig. 6k/l), the ideal benchmark test case displayed the highest stiffness and lowest local and mean stress, which is to be expected given that it is not limited 
by perimeter and infill constraints. The MPS yielded the highest overall structural performance with up to three times lower sum of strain energies and $\sim 40 \%$ lower maximum stress. The concentric, MAT and $0^{\circ} / 90^{\circ}$ grid infill had comparable performance, while the $\pm 45^{\circ}$ grid pattern was underperforming. The higher stiffness of the $0^{\circ} / 90^{\circ}$ grid infill over the $\pm 45^{\circ}$ grid variant stems from the $0^{\circ}$ layer, which is well-aligned with the principal stresses.

\subsection{The influence of fibre angle deviation}

Fig. 7a-d) illustrates the element-wise agreement between the printed bead orientation and the theoretically ideal material orientation of the benchmark. With just over $50 \%$ agreement, the grid infill patterns display overall the lowest adherence to the stress trajectories; however, it yielded a more homogeneous distribution and a better agreement at the critical regions around the holes and at the edges where the load is applied (pronounced edge effect due to $90^{\circ}$ misaligned paths). The MAT-based infill did not improve the alignment over the generic concentric infill in these case studies. MPS displayed the best agreement (85-92\%).

a) $53.6 \%$ b) $83.6 \%$ $72.1 \%$

c) $80.9 \%$

d) $91.8 \%$

$84.5 \%$

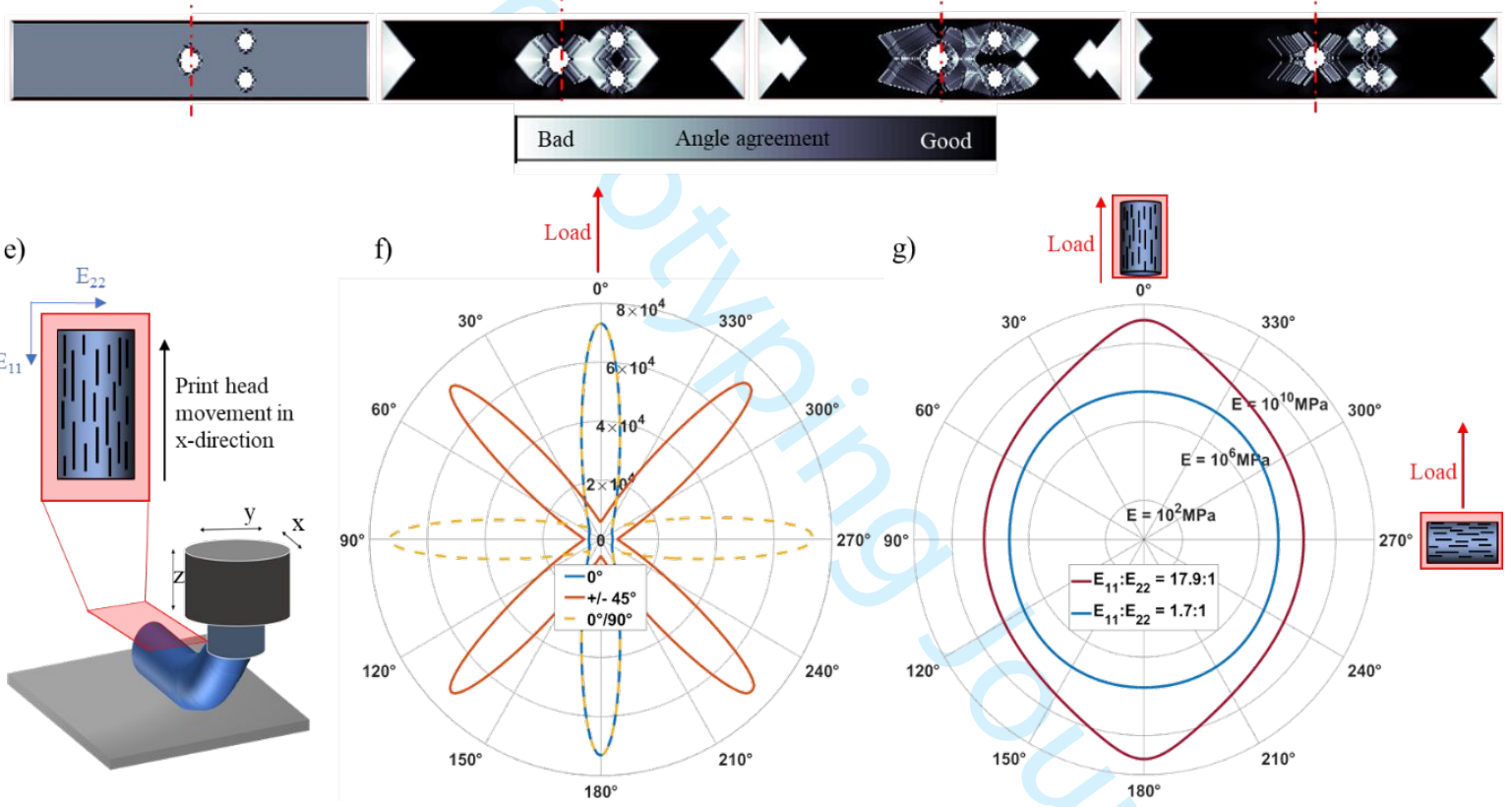

Fig. 7: a-d) Percentage agreement between the element-wise orientation of the toolpath and the benchmark stress trajectories in the a) grid infill ( $\pm 45^{\circ}$ variant displayed), b) the concentric, c) the MAT, and d) the MPS infill patterns for the open hole test cases. Note that the two different grid layups have comparable agreements. e) Schematic of the printer head, showing the alignment of the fibres with the printing direction, constituting the principal material direction. $\mathrm{f} / \mathrm{g}$ ) Polar plots highlighting the elastic constants $\mathrm{E}_{11}$ and $\mathrm{E}_{22}$ in a global coordinate system concerning the loading direction as a function of the f) fibre direction and layup as well as g) the degree of material orthotropy (C-FRAM vs S-FRAM).

Simply considering each element with a specific print path orientation as lamina, the stiffness in a global coordinate system as a function of fibre orientation and material orthotropy can be determined, as shown in Fig. 7f/g). Assuming that the principal material direction of an element is orientated parallel to the loading direction, the maximum stiffness is obtained. How the elastic constants change with the loading direction determines the achievable stiffness. As the grid patterns have different toolpath orientations through the thickness, their variation in 
stiffness is more balanced as shown in Fig. 7f)) and thus less susceptibility to the reduction in stiffness. The higher the level of orthotropy, the more significant the decrease in stiffness for misaligned fibres (Fig. 7g)).

Recalling Fig. 6k/l), the $\pm 45^{\circ}$ grid infill performed the worst while having a negligible number of entirely misaligned fibres (i.e. by $90^{\circ}$ ) but a low overall agreement (Fig. 7a)). The $0^{\circ} / 90^{\circ}$ grid variant, on the other hand, performed well while having a similar overall percentage agreement between the principal stresses and the fibre angle (average fibre angle between the two layers), however, with one of the layers being highly misaligned. Therefore, the stiffnessalignment index is introduced, combining the global sensitivity to misalignment with the local stress intensity to better capture and estimate the performance (see Fig. 8).

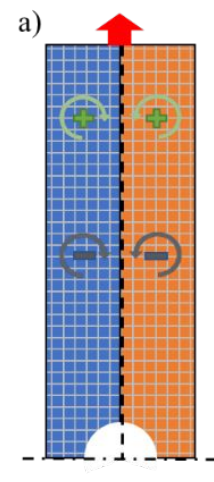

b)
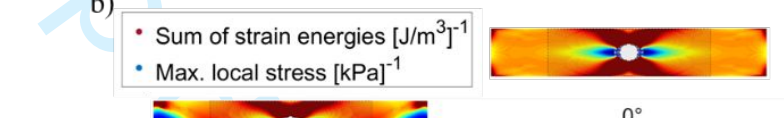

c)

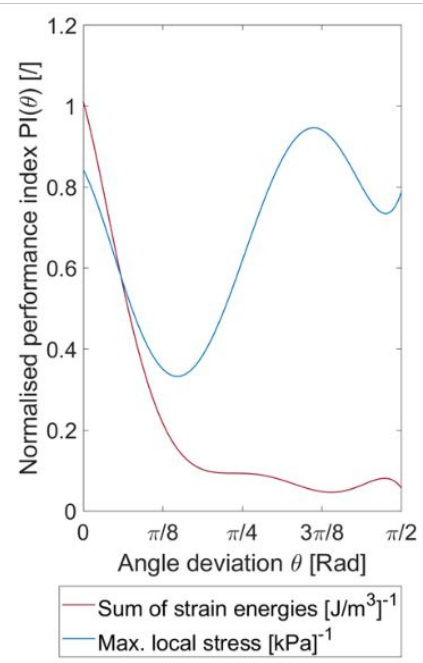

d)

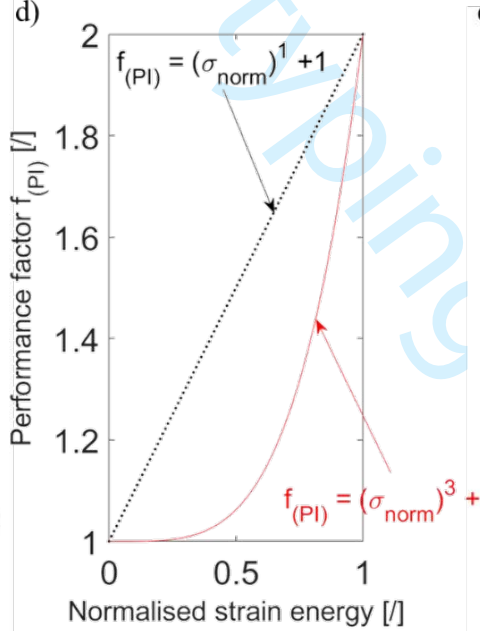

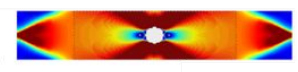

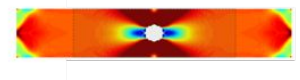

$-90^{\circ}$

e)

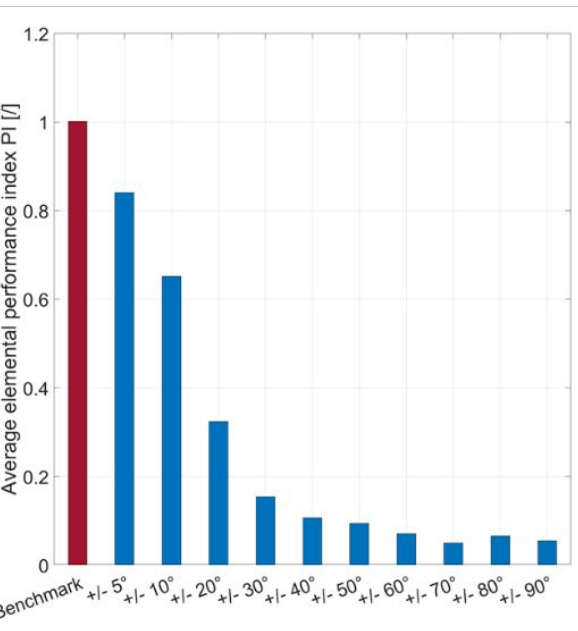

Fig. 8: Fibre angle sensitivity analysis of the benchmark solution for case study I) and the trend of the stiffnessalignment performance index. a) Element-wise rotation scheme of fibre angles in clock- and anti-clockwise direction to preserve symmetry, yielding the b) sum of global strain energies and maximum local stress as a function of the angle deviation, including the strain energy distribution and c) the corresponding polynomial fits for the normalised performances $\operatorname{PI}(\theta)$. d) Penalisation factor $(\mathrm{p}=3)$ used to adjust the elemental score before determining the e) average performance index $P I$.

The principal material directions were initially aligned with the principal stress trajectories (recall 3.1) to obtain the benchmark performance. By element- and step-wise rotation of the principal material direction under consideration of symmetry, strain energy and stress performance curves were obtained (see Fig. 8c)). Subsequently, the elemental stress 
intensity was factorised into elemental score $P I(\theta)$. Finally, element scores were averaged, which yielded the stiffness-alignment index $P I$, as described in paragraph 2.2.

\subsection{The influence of the geometrical complexity on the assessment indices}

Overall, Fig. 10 summarises the achieved scores for each index, highlighting dependencies between them and providing better design choices based on a given objective (e.g. lowest print time is prioritised). In the following, each corresponding DfAM factor will be discussed individually based on the key metrics stated in Table 3.

Economy - The concentric infill was the most cost-efficient strategy as CPU and print time are most favourable. The additional FEA step required for MPS made it the slowest regarding computational time, however, by less than $10 \%$ compared to the concentric option. The print time for the $\pm 45^{\circ}$ grid infill was $\sim 25 \%$ greater than the fastest strategy (concentric). However, it incorporates excessive print head movements; thus, a continuous and meandering implementation would have reduced the time (e.g. compare implementation shown in Fig. 3h)). The MAT and MPS infills required more iterative loops to define the paths explicitly due to the toolpath simplification steps (refer to section 2.1.2). Between cases I) and II) the CPU time changed in favour of MAT. It is more rapidly capturing the critical geometrical features despite the increased number of boundaries.

Performance - The MPS strategy yielded the lowest sum of strain energies and lowest maximum stress, making it the stiffest and potentially strongest pattern. The second-highest performance was recorded for the $0^{\circ} / 90^{\circ}$ grid infill, mainly driven by the $0^{\circ}$ layer, representing an almost ideal alignment for this test case. Similar strain energy and stress values were observed in the concentric and MAT infill. However, the former displayed elements with infinitely small strain in the multi open-hole case, contributing little to the load-bearing capability and thus indicating an inefficient pattern. It was found that the edge-effect was pronounced where the loads were applied in all specimens but the ones based on the grid infills (see Fig. 9). This stems from numerous toolpaths aligned orthogonal to the loading direction in the vicinity of the loading edges in the concentric and adaptive patterns, which caused high strain energy in those elements.

In both test cases, the $\pm 45^{\circ}$ grid infill displayed the highest sum of strain. Areas of high strain were limited to the perimeters instead of the $0^{\circ} / 90^{\circ}$ grid infill, displaying additional highstress regions around the holes. The mean and standard deviation of the local stresses was highest for the $0^{\circ} / 90^{\circ}$ grid infill, stemming from oppositely aligned fibres in the two layers, making the interlaminar strength and, consequently, manufacturing quality pivotal in achieving this performance. As this has not been considered in the FEA, it can be assumed that its performance might be overestimated. The concentric and both adaptive patterns achieved low mean stresses in the local area. In addition, a significantly lower maximum stress was recorded for the MPS infill compared to the $\pm 45^{\circ}$ grid pattern. This ratio between the maximum and average local stress was exceptionally high for the concentric infill, resonating with the lack of homogeneity, as shown in Fig. 7. 
The stiffness-alignment index, introduced in 3.2, was found to constitute a reasonable estimate for the performance, i.e. was in good agreement with the recorded sum of strain energies (see Fig. 10). Opposite to comparing the general agreement of paths and principal stress (compare Fig. 7a-d)), it did estimate the performance better. Only the $P I$ of the $0^{\circ} / 90^{\circ}$ grid infill did not adhere to the expected stiffness value as merely the $0^{\circ}$ paths contributed to the stiffness, while the second layer does not and is hence skewing the result.

Manufacturability - While only the concentric infill provided consistently good results regarding the percentage of path lengths above $40 \mathrm{~mm}$, the grid infills outperformed in sinuosity index. Both factors are considered vital for a good result when printing with continuous fibres, but only MAT and MPS patterns could achieve a good compromise, deeming them most suitable for C-FRAM. While the variation in performance in these two categories ranged by only $\sim 20 \%$ for $S I$, the differences were more significant in terms of minimum fibre length, virtually rendering the $\pm 45^{\circ}$ grid pattern inapplicable for C-FRAM.

a)
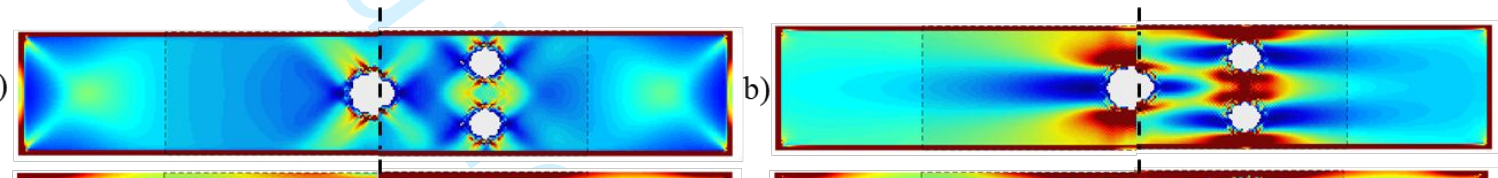

c)
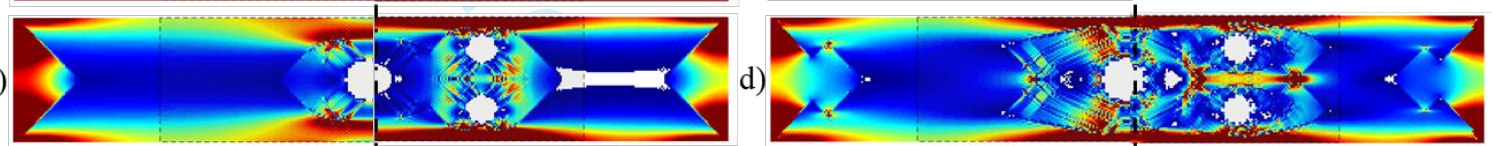

e)

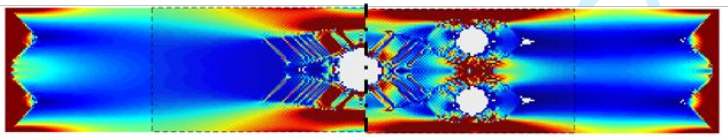

Min

Max

Fig. 9: Strain energy distribution of the single and multiple open-hole case studies (split-view) for the a) $\pm 45^{\circ}$ grid, b) $0^{\circ} / 90^{\circ}$ grid, c) concentric, d) MAT and e) MPS infill strategy. Note: The strain energy scale is not universal; instead, the bounds in each test case were adjusted for best visualisation.

DfAM interdependencies - The relation between the print time and path length was confirmed, which yielded good performances for both the concentric and MPS infills, stemming from the continuity in which layers were printed. This avoided excessive extrusionfree tool-movements, which would increase the required time. Thus, they are deemed the most suitable for using C-FRAM from a fabrication standpoint and likely from a performance point of view as a higher fibre volume fraction can be realised (see paragraph 2.2). In summary, Fig. 10 elucidates that while the MPS displayed the best overall structural performance for this test case, the concentric and MAT patterns achieved a good balance across all categories. Regarding the relation between the $S I$ index and performance, it is known that excessive fibre undulation impairs the structural performance not only of fibre-reinforced composites generally but also for AM-parts as it results in higher porosity. This is a particular issue for CFRAM. Thus, the infills with high SI values (see, e.g. concentric infill in Fig. 10) might overestimate the achievable structural performance in the printed part. 
a)

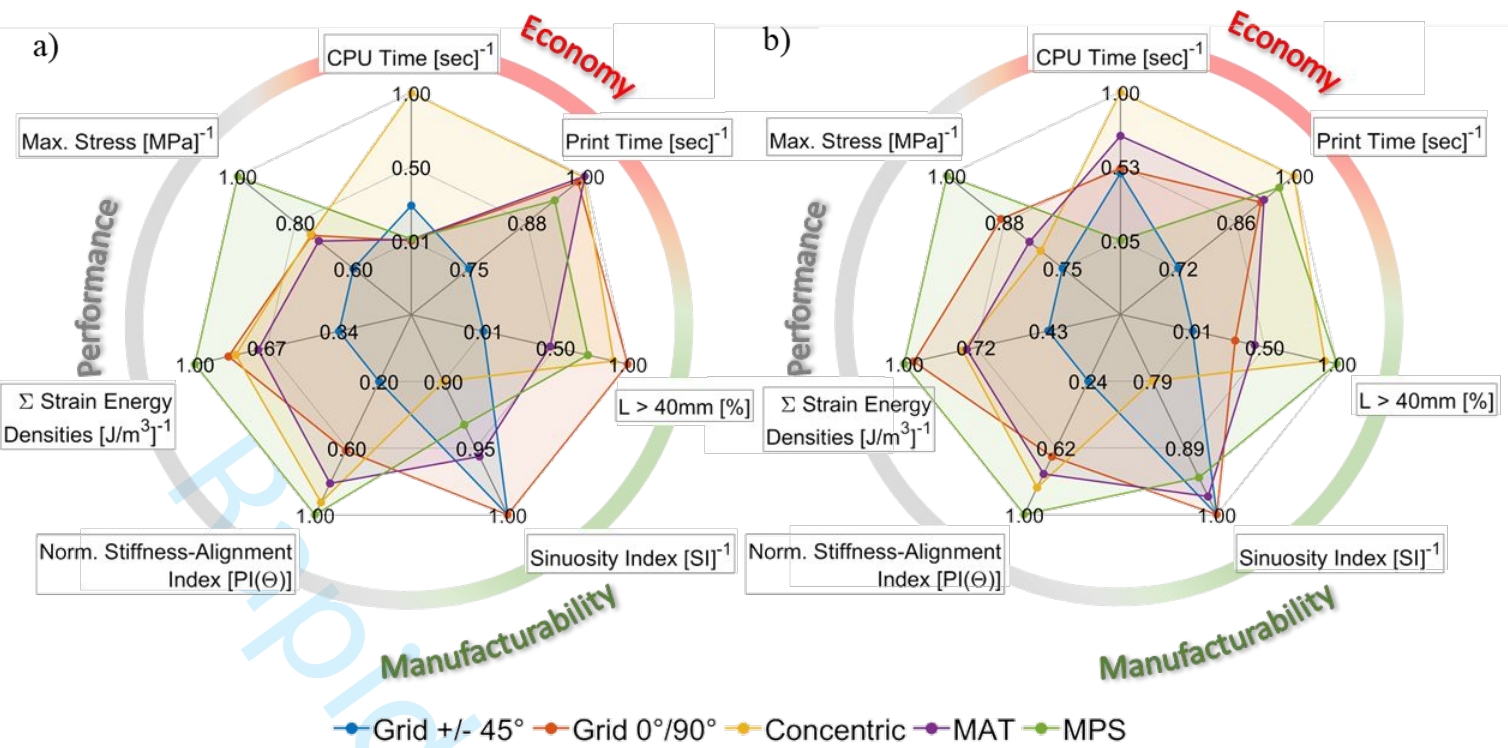

Fig. 10: Normalised performance indices of different DfAM factors for the a) single and b) multiple hole case studies subject to the five different infill patterns. (Spider plot visualisation adapted from [112]).

\subsection{The influence of material orthotropy (C-FRAM vs S-FRAM)}

Fig. 11a-d) exemplarily displays the two adaptive infill patterns used to model and print the test case III). Additionally, Fig. 12 summarises the DfAM factors, assuming either CFRAM or S-FRAM properties. While the focus lies on the performance factor, it must be noted that similar to case study I), both the MAT and concentric infills achieved a good average score across all seven indices.

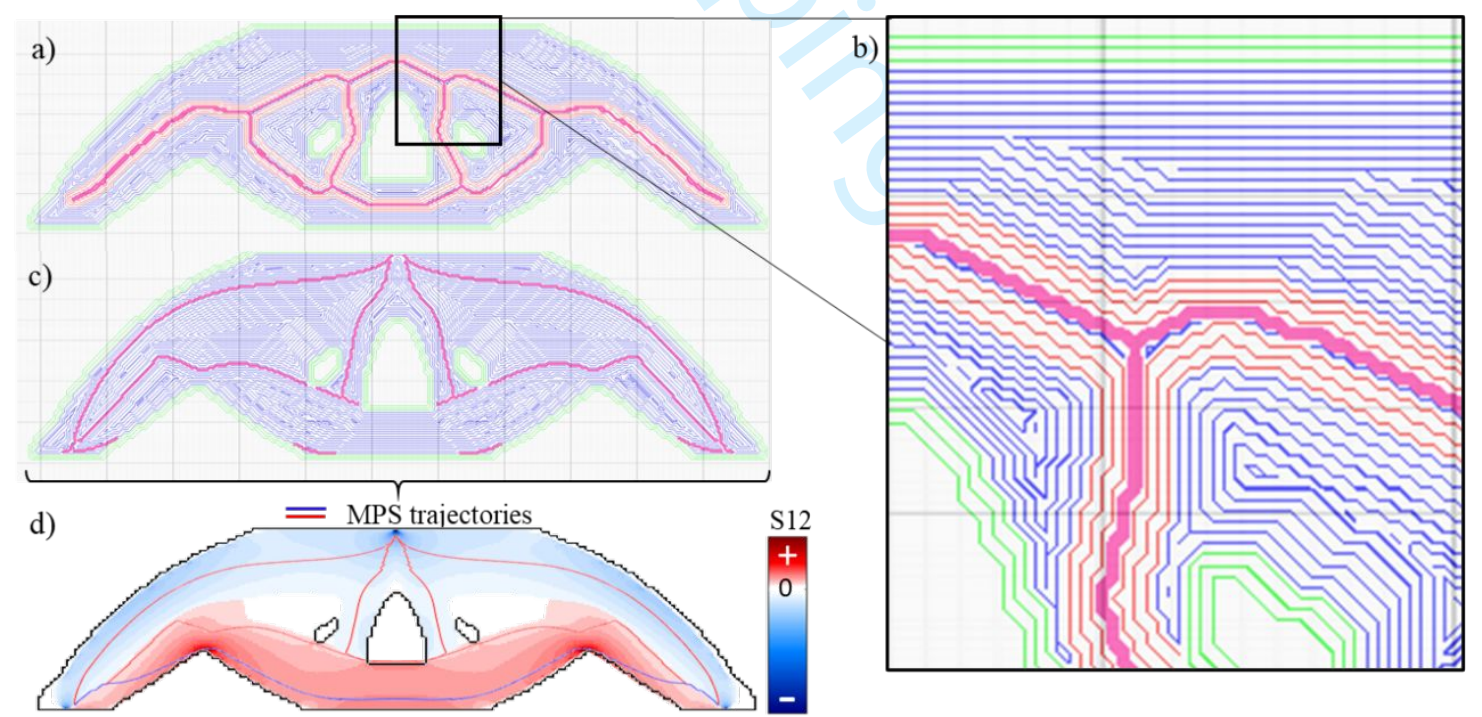

Fig. 11: Visualisation of a) MAT and c) MPS infill patterns employed for the TO-3PB test case. c) Close-up of the MAT infill pattern. d) A shear stress diagram, including the main principal stresses, highlight the guiding print paths used for the MPS strategy.

For the test case, assuming the C-FRAM properties, the grid infill showcased high strain areas at the loading point and in the shell region, whereas the other infills displayed high strains at the loading point and the recess close to the support points (see Fig. 13). On the contrary, 
the S-FRAM tests cases displayed a similar strain distribution. Overall, this was reflected in the performance indices, as the MPS infill yielded the highest stiffness and strength with CFRAM, followed by the concentric and MAT infills. In contrast, with S-FRAM, both the sum of strain energies and maximum stress varied less across the infills (see Fig. 12). Besides the differences regarding the mechanical performance, it was found that the MAT infill strategies - analogue to the open-hole case study - achieved a good compromise between the DfAM factors.

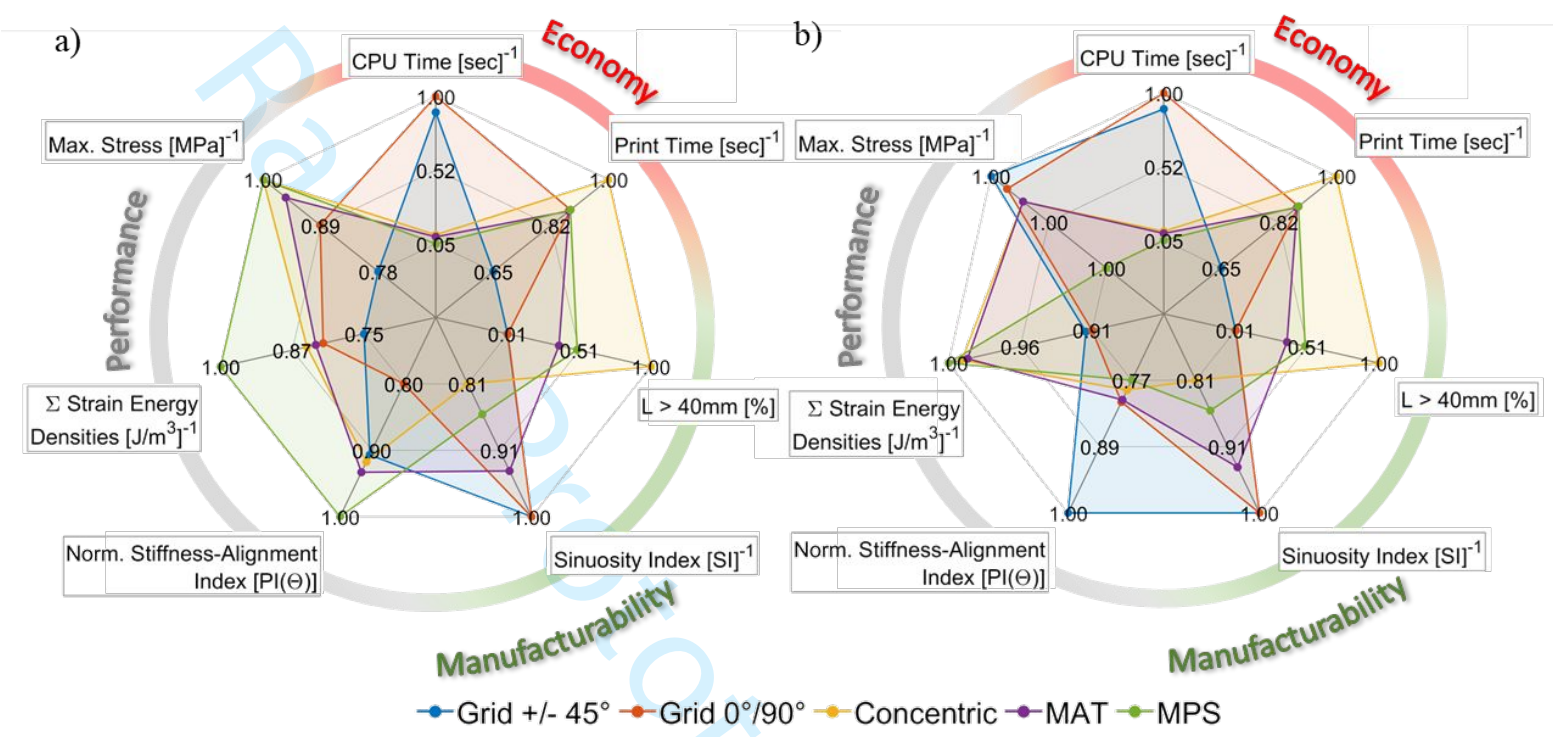

Fig. 12: Normalised indices of different DfAM factors for case study III) considering a fibre-reinforced material with a a) high (C-FRAM) and b) low (S-FRAM) level of orthotropy subject to the five different infill patterns. (Spider plot visualisation adapted from [112]).

It was noted that the stiffness-alignment index, introduced in 3.2, constitutes a reasonable estimate for the performance of C-FRAM, i.e. is in good agreement with the recorded sum of strain energies (see Fig. 10 and Fig. 11a)). However, it is not suitable when used with material properties with a low level of orthotropy (compare Fig. 11b/c)). Likewise, a similar ranking was achieved concerning the maximum stress, i.e. the strength of the part till yield. Significantly higher susceptibility to a fibre angle deviation from the benchmark case was observed for the high-performance feedstock material (performance drop $\sim 90 \%$ for CFRAM as opposed to $\sim 40 \%$ for S-FRAM).

These findings emphasise that for C-FRAM, good alignment is crucial, making it pivotal to tailor the tool paths. Consequently, it remains a necessity for slicing software specialised in C-FRAM to expand the infill capabilities of traditional slicers and incorporate adaptive strategies that exploit the potential of using high stiffness fibres, primarily as it is geared towards end-use parts. While these performance gains or losses might seem marginal, it is important to realise that this study only looks at two individual slices, whereas printed builds are often composed of hundreds of layers. Thus, suggesting more significant improvements in performance for the entire structure. 

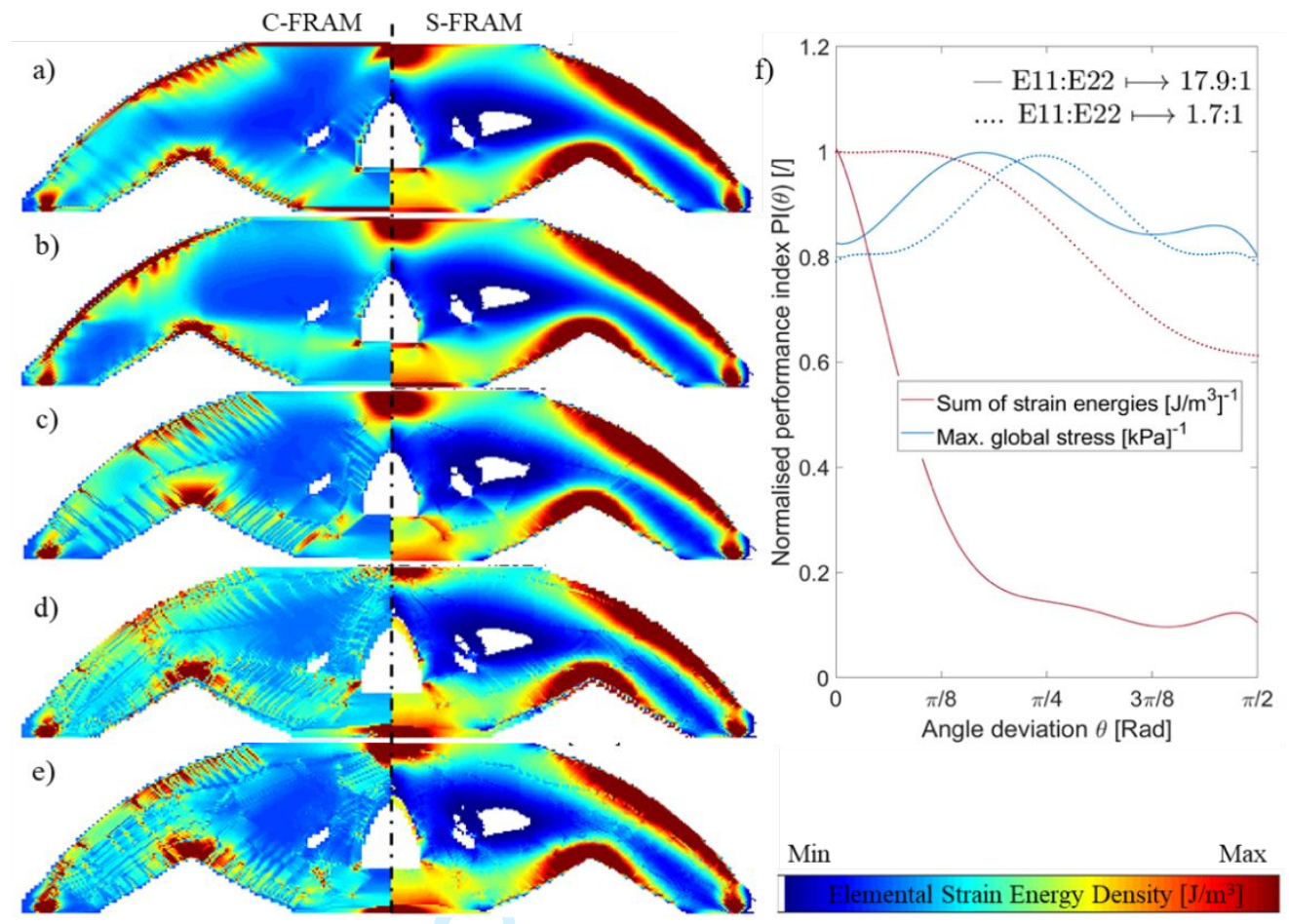

Fig. 13: Strain energy distribution of the case study III) considering either C-FRAM or S-FRAM properties (split-view) for the a) $\pm 45^{\circ}$ grid, b) $0^{\circ} / 90^{\circ}$ grid, c) concentric, d) MAT and e) MPS infill strategy. Note: The strain energy scale is not universal; instead, the bounds in each test case were adjusted for best visualisation. $\mathrm{f}$ ) Normalised performance index a function of fibre angle deviation from principal stresses.

Multi-material printing - The previous studies have assumed single-material prints mainly for continuous fibres; however, the hardware-specific minimum fibre length (recall Fig. 4) was not considered. Thus, in reality, it would not have been possible to print those parts entirely with C-FRAM. Consequently, it was suggested that the performance was overestimated, yielding no definitive conclusion on the dependence between manufacturability and stiffness/maximum stress. Hence, case studies I) and III) are reiterated assuming coextrusion with both C-FRAM and S-FRAM. At the same time, the former is naturally prioritised in pursuit of maximum performance (see Fig. 14). It was observed that the $\pm 45^{\circ}$ grid infill was inferior in both cases for the sum of strain energies and maximum stress. While significant enhancement in stiffness was found for the tension specimens for all remaining infills, under bending, the concentric, MAT and MPS infills outperform the grid variants. As the $0 / 90^{\circ}$ infill can only partially be printed using C-FRAM for case III), it yielded minimal improvements. A similar trend was observed for the maximum stress. The concentric and MPS infills showcased the highest reduction in stress by almost $50 \%$ and $40 \%$ for tests case I) and III), respectively.

These findings constitute proof of the interdependency between manufacturability with C-FRAM and performance. As shown in the spider plot in Fig. 12, the concentric and MPS infill showed the highest percentage of paths with sufficient length for printing continuous fibres. Thus, the positive correlation has been proven and should be considered in the design with C-FRAM. 


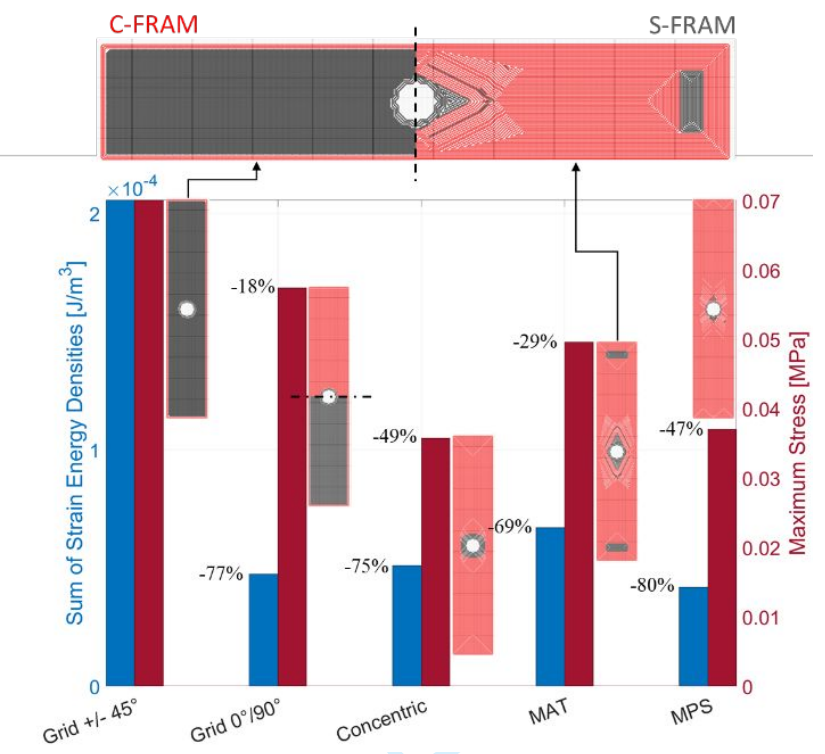

a)

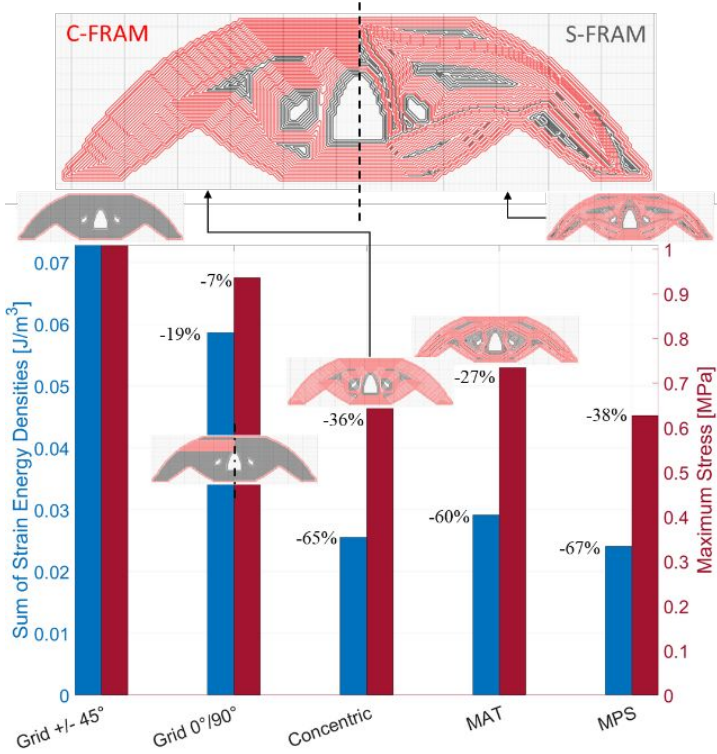

b)

Fig. 14: Bar plots comparing the sum of strain energies and maximum stress for the multi-material prints of test cases a) Open-Hole and b) TO-3PB, including individual images highlighting the area where continuous (grey) or short (red) fibre-reinforced print material were used.

\subsection{Experimental verification of DfAM factor performance}

Extruded versions of the 2D topology were printed using S-FRAM to validate the FEAs (recall 3.4). Note that only the $\pm 45^{\circ}$ variant of the grid infill was tested. Stiffness and ultimate strength were deduced from the load-displacement data, as shown in Fig. 15. The MAT infill was found to have the highest stiffness and ultimate strength, whereas the MPS infill enqueues at the lower end of the performance spectrum. The grid infill shows overall a significantly higher variability in performance.
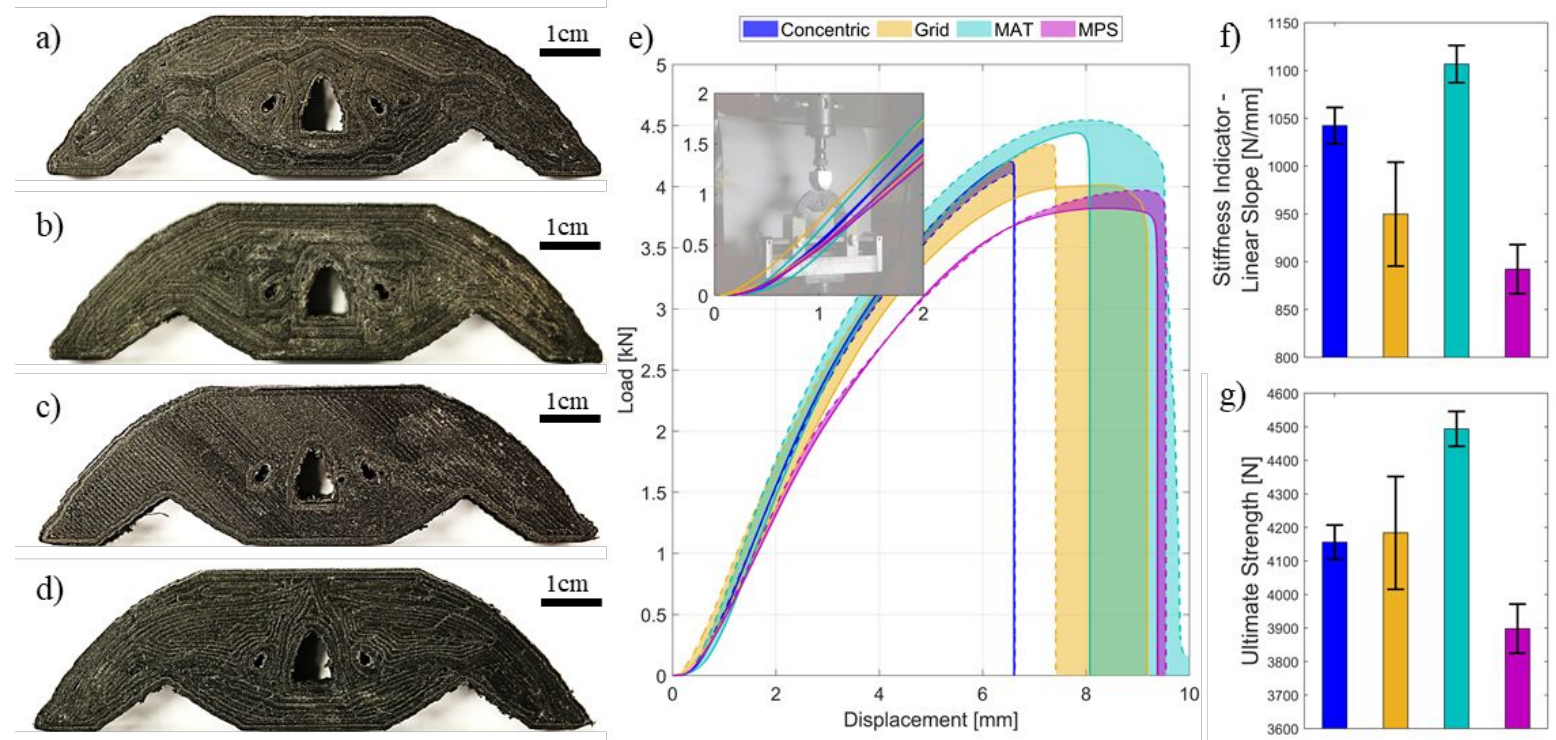

Fig. 15: a-d) Printed short fibre-reinforced 3PB test specimens with a) MAT, b) concentric, c) $\pm 45^{\circ}$ grid, and d) MPS infill. e) Load-displacement curves and corresponding bar plots for $f$ ) the stiffness and g) the ultimate bending strength. 
Generally, a difference in maximum and minimum stiffness and strength of $\sim 20 \%$ and $\sim 15 \%$, respectively, was observed. In comparison, a 10\% difference in stiffness and equal strength was suggested numerically (compare Fig. 12b)), thus being generally in good accordance. One reason that the MAT infill performed well might stem from a high angle agreement in combination with a reasonably good score for fibre undulation, i.e. sinuosity index (compare Fig. 12b)), which promotes low porosity and thus higher performance. Other aspects of manufacturability affecting the performance, including the inter-bead and inter-layer bonding (determined by the degree of solidification, meaning the duration for an adjacent path/layer to be printed), were not examined in this work but may explain the differences in performance. Moreover, this study did not consider interlaminar shear stresses, potentially revealing more or less favourable infill patterns and stacking sequences.

Fig. 16 displays the fractography images of the bending specimens. Except for one MAT coupon, all specimens failed abruptly, i.e. catastrophically, primarily at the point where the strain energy was identified as high and sharp geometry changes were present (compare Fig. 13a-e)). Only the concentric specimens failed centrally between loading and support pins, possibly due to the numerous paths orientated $90^{\circ}$ to the loading direction in the vicinity of the loading point.

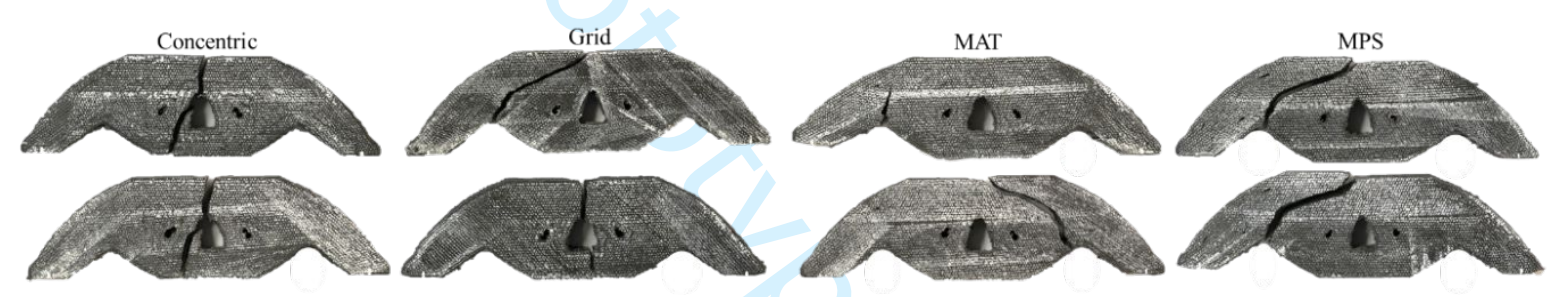

Fig. 16: Macroscopic fractography of the TO-3PB specimens

\section{Conclusions and Future Work}

This work has compared two conventional infill patterns used in FRAM, namely grid and concentric, with two novel adaptive strategies termed MAT and MPS, derived from the medial axis (geometry-driven) and guided by the principal stresses, respectively. This comparison was completed considering the DfAM factors i) performance, ii) economy and iii) manufacturability. Seven related indices exemplified the mechanical (sum of strain energies and maximum stress), economical (CPU time and print time) and processing-related (path lengths and sinuosity index) performance subject to short and continuous fibre-reinforced AM (S/C-FRAM) from a numerical and experimental viewpoint. Benchmark structural performances were established, aligning the fibre orientation with the principal stresses without considering typical slicer constraints (e.g., shell layers, continuity of paths, et cetera). Their sensitivity to fibre angle deviation was investigated, and a stiffness-alignment index was introduced, which transpired to be efficient in estimating the performance for C-FRAM. In summary, the following conclusions were drawn:

- The concentric infill scored highest for both print time and percentage of toolpaths greater than the hardware-specific minimum fibre length (guaranteeing the use of continuous 
fibres). The grid infills generally performed poorly in those categories. Although, it ensured low fibre undulation, which is critical for the manufacturability with C-FRAM and guarantees low porosity prints. MAT and MPS displayed an excellent compromise between print time, path length, and sinuosity thus deemed a promising contender for printing with continuous fibres.

- The MPS strategy yields the highest stiffness (lowest sum of strain energies) and potentially highest strength (lowest maximum stress) if feedstock with continuous fibre-reinforcement is considered. However, differences in mechanical performance vanish for materials with a low degree of material orthotropy, like those used in S-FRAM, which was verified in an experimental investigation.

- The stiffness-alignment performance index constitutes a good estimator for the performance for C-FRAM but less for S-FRAM. A positive correlation between a high percentage of sufficiently long paths, guaranteeing the use of C-FRAM (high fibre volume fraction), and high stiffness and low maximum stress was determined considering multimaterial prints with short and continuous fibres.

- The infills scored differently regarding the DfAM factors, depending on the case study and loading scenario. Thus, an automated and simulation-assisted Slicer outputting custom toolpath strategy not only on a case-by-case but also on a slice-by-slice basis is recommended.

Accounting for interlaminar stresses could be the subject of future work, concurrently optimising the infill strategy and stacking sequence. Ongoing work ought to focus on portraying the correlation between indicators for manufacturability and performance better, especially considering C-FRAM as the placement, continuity or low fibre undulation become increasingly important in achieving high performance. Consequently, more advanced toolpath approaches, better leveraging the DfAM factors could materialise.

\section{ACKNOWLEDGEMENTS}

The Department of Aeronautics at Imperial College London and The Engineering and Physical Sciences Research Council (EPSRC) supported and funded this work with the project reference 2091639. The authors would also like to acknowledge the contribution of Shreeyam Kacker in developing the 3D printer.

\section{REFERENCES}

[1] S. Hamid, R. Sanei, 3D-Printed Carbon Fiber Reinforced Polymer Composites : A Systematic Review, J. Compos. Sci. 4 (2020). doi:doi:10.3390/jcs4030098.

[2] D. Zindani, K. Kumar, An insight into additive manufacturing of fiber reinforced polymer composite, Int. J. Light. Mater. Manuf. 2 (2019) 267-278. doi:10.1016/j.ijlmm.2019.08.004.

[3] G.D. Goh, Y.L. Yap, S. Agarwala, W.Y. Yeong, Recent Progress in Additive Manufacturing of Fiber Reinforced Polymer Composite, Adv. Mater. Technol. 1800271 (2018). doi:10.1002/admt.201800271.

[4] A.N. Dickson, J.N. Barry, K.A. McDonnell, D.P. Dowling, Fabrication of continuous 
carbon, glass and Kevlar fibre reinforced polymer composites using additive manufacturing, Addit. Manuf. 16 (2017) 146-152. doi:10.1016/j.addma.2017.06.004.

] G.D. Goh, V. Dikshit, A.P. Nagalingam, G.L. Goh, S. Agarwala, S.L. Sing, J. Wei, W.Y. Yeong, Characterization of mechanical properties and fracture mode of additively manufactured carbon fiber and glass fiber reinforced thermoplastics, Mater. Des. 137 (2018) 79-89. doi:10.1016/j.matdes.2017.10.021.

[6] J.Y. Choi, M.T. Kortschot, Stiffness prediction of 3D printed fiber-reinforced thermoplastic composites, Rapid Prototyp. J. (2019). doi:10.1108/RPJ-11-2018-0283.

[7] S. Liu, Y. Li, N. Li, A novel free-hanging 3D printing method for continuous carbon fiber reinforced thermoplastic lattice truss core structures, Mater. Des. 137 (2018) 235244. doi:10.1016/j.matdes.2017.10.007.

[8] M. Eichenhofer, J.C.H. Wong, P. Ermanni, Continuous lattice fabrication of ultralightweight composite structures, Addit. Manuf. 18 (2017) 48-57. doi:10.1016/j.addma.2017.08.013.

[9] Composite 3D Printing, Markforged, Inc. (2017). https://markforged.com/composites/ (accessed December 14, 2017).

[10] Continuous Fiber 3D Printing, Contin. Compos. (2017). http://continuouscomposites.com/ (accessed December 14, 2017).

[11] 9T Labs - Mission, 9T Labs. (2018). https://www.9tlabs.com/ (accessed October 4, 2018).

[12] P. Parandoush, D. Lin, A review on additive manufacturing of polymer-fiber composites, Compos. Struct. 182 (2017) 36-53. doi:10.1016/j.compstruct.2017.08.088.

[13] D.A. Türk, R. Kussmaul, M. Zogg, C. Klahn, B. Leutenecker-Twelsiek, M. Meboldt, Composites Part Production with Additive Manufacturing Technologies, Procedia CIRP. 66 (2017) 306-311. doi:10.1016/j.procir.2017.03.359.

[14] I. Fidan, A. Imeri, A. Gupta, S. Hasanov, A. Nasirov, A. Elliott, F. Alifui-Segbaya, N. Nanami, The trends and challenges of fiber reinforced additive manufacturing, Int. J. Adv. Manuf. Technol. (2019). doi:10.1007/s00170-018-03269-7.

[15] P. Parandoush, D. Lin, A review on additive manufacturing of polymer-fiber composites, Compos. Struct. 182 (2017) 36-53. doi:10.1016/j.compstruct.2017.08.088.

[16] P. Zhang, J. Liu, A.C. To, Role of anisotropic properties on topology optimization of additive manufactured load bearing structures, Scr. Mater. 135 (2017) 148-152. doi:10.1016/j.scriptamat.2016.10.021.

[17] J.R. Raney, B.G. Compton, J. Mueller, T.J. Ober, K. Shea, J.A. Lewis, Rotational 3D printing of damage-tolerant composites with programmable mechanics, in: Proc. Natl. Acad. Sci., 2018: pp. 1-6. doi:10.1073/pnas.1715157115.

[18] B.G. Compton, J.A. Lewis, 3D-printing of lightweight cellular composites, Adv. Mater. 26 (2014) 5930-5935. doi:10.1002/adma.201401804.

[19] Z. Quan, Z. Larimore, A. Wu, J. Yu, X. Qin, M. Mirotznik, J. Suhr, J.H. Byun, Y. Oh, T.W. Chou, Microstructural design and additive manufacturing and characterization of 3D orthogonal short carbon fiber/acrylonitrile-butadiene-styrene preform and composite, Compos. Sci. Technol. $126 \quad$ (2016) 139-148. doi:10.1016/j.compscitech.2016.02.021.

[20] H.L. Tekinalp, V. Kunc, G.M. Velez-Garcia, C.E. Duty, L.J. Love, A.K. Naskar, C.A. Blue, S. Ozcan, Highly oriented carbon fiber-polymer composites via additive manufacturing, Compos. Sci. Technol. $105 \quad$ (2014) 144-150. doi:10.1016/j.compscitech.2014.10.009.

[21] J.P. Lewicki, J.N. Rodriguez, C. Zhu, M.A. Worsley, A.S. Wu, Y. Kanarska, J.D. Horn, E.B. Duoss, J.M. Ortega, W. Elmer, R. Hensleigh, R.A. Fellini, M.J. King, 3D-Printing of Meso-structurally Ordered Carbon Fiber/Polymer Composites with Unprecedented 
Orthotropic Physical Properties, Sci. Rep. 7 (2017) 1-14. doi:10.1038/srep43401.

[22] T. Letcher, M. Wayatashek, Material Property Testing of 3D-Printed Specimen in PLA on an Entry-Level 3D Printer, in: IMECE - Proc. ASME 2014 Int. Mech. Eng. Congr. Expo., Montreal, Quebec (Canada), 2014: pp. 1-8.

[23] T.D. McLouth, J. V. Severino, P.M. Adams, D.N. Patel, R.J. Zaldivar, The impact of print orientation and raster pattern on fracture toughness in additively manufactured ABS, Addit. Manuf. 18 (2017) 103-109. doi:10.1016/j.addma.2017.09.003.

[24] A. Bellini, S. Güçeri, Mechanical characterization of parts fabricated using fused deposition modeling, Rapid Prototyp. J. 9 (2003) 252-264. doi:10.1108/13552540310489631.

[25] M. Ivey, G.W. Melenka, J.P. Carey, C. Ayranci, Characterizing short-fiber-reinforced composites produced using additive manufacturing, Adv. Manuf. Polym. Compos. Sci. 3 (2017) 81-91. doi:10.1080/20550340.2017.1341125.

[26] F. Ning, W. Cong, J. Qiu, J. Wei, S. Wang, Additive manufacturing of carbon fiber reinforced thermoplastic composites using fused deposition modeling, Compos. Part B Eng. 80 (2015) 369-378. doi:10.1016/j.compositesb.2015.06.013.

[27] C. Yan, L. Hao, L. Xu, Y. Shi, Preparation, characterisation and processing of carbon fibre/polyamide-12 composites for selective laser sintering, Compos. Sci. Technol. 71 (2011) 1834-1841. doi:10.1016/j.compscitech.2011.08.013.

[28] J. Mueller, J.R. Raney, K. Shea, J.A. Lewis, Architected Lattices with High Stiffness and Toughness via Multicore-Shell 3D Printing, Adv. Mater. 30 (2018) 1-8. doi:10.1002/adma.201705001.

[29] S. Malek, J.R. Raney, J.A. Lewis, L.J. Gibson, Lightweight 3D cellular composites inspired by balsa, Bioinspiration and Biomimetics. 12 (2017) 1-11. doi:10.1088/17483190/aa6028.

[30] X. Tian, T. Liu, C. Yang, Q. Wang, D. Li, Interface and performance of 3D printed continuous carbon fiber reinforced PLA composites, Compos. Part A Appl. Sci. Manuf. 88 (2016) 198-205. doi:10.1016/j.compositesa.2016.05.032.

[31] C. Yang, X. Tian, T. Liu, Y. Cao, D. Li, 3D printing for continuous fiber reinforced thermoplastic composites : mechanism amd peroformance, Rapid Prototyp. J. 23 (2017) 209-215. doi:10.1108/RPJ-08-2015-0098.

[32] S.A. Hinchcliffe, K.M. Hess, W. V. Srubar, Experimental and theoretical investigation of prestressed natural fiber-reinforced polylactic acid (PLA) composite materials, Compos. Part B Eng. 95 (2016) 346-354. doi:10.1016/j.compositesb.2016.03.089.

[33] G.W. Melenka, B.K.O. Cheung, J.S. Schofield, M.R. Dawson, J.P. Carey, Evaluation and prediction of the tensile properties of continuous fiber-reinforced $3 \mathrm{D}$ printed $\begin{array}{llll}\text { structures, } & \text { Compos. } & \text { Struct. } & 153\end{array}$ (2016) 866-875. doi:10.1016/j.compstruct.2016.07.018.

[34] J. Pu, P. Zhuo, A. Jones, S. Li, I. Ashcroft, T. Yang, K. Ponggorn, Temperature Control of Continuous Carbon Fibre Reinforced Thermoplastic Composites By 3D Printing, 21st Int. Conf. Compos. Mater. (2017) 20-25.

[35] N. Li, Y. Li, S. Liu, Rapid prototyping of continuous carbon fiber reinforced polylactic acid composites by 3D printing, J. Mater. Process. Technol. 238 (2016) 218-225. doi:10.1016/j.jmatprotec.2016.07.025.

[36] X. Tian, T. Liu, Q. Wang, Manufacturing and Recycling of 3D Printed Continuous Carbon Fiber Reinforced PLA Composites, in: 21st Int. Conf. Compos. Mater., 2017: pp. 1609-1618. doi:10.1016/j.jclepro.2016.11.139.

[37] Y. Nakagawa, K. ichiro Mori, T. Maeno, 3D printing of carbon fibre-reinforced plastic parts, Int. J. Adv. Manuf. Technol. 91 (2017). doi:10.1007/s00170-016-9891-7.

[38] T.H.J. Vaneker, Material Extrusion of Continuous Fiber Reinforced Plastics Using 
Commingled Yarn, Procedia CIRP. $66 \quad$ (2017) 317-322. doi:10.1016/j.procir.2017.03.367.

[39] J. Plocher, A. Panesar, Next-Generation Fibre-Reinforced Lightweight Structures for Additive Manufacturing, in: 29th Annu. Int. Solid Free. Fabr. Symp., Austin, Texas, USA, 2018: pp. 664-684.

[40] M. Eichenhofer, J.C.H. Wong, P. Ermanni, Exploiting cyclic softening in continuous lattice fabrication for the additive manufacturing of high performance fibre-reinforced thermoplastic composite materials, Compos. Sci. Technol. 164 (2018) 248-259. doi:10.1016/J.COMPSCITECH.2018.05.033.

[41] Z. Hou, X. Tian, J. Zhang, D. Li, 3D printed continuous fibre reinforced composite corrugated structure, Compos. Struct. $184 \quad$ (2018) 1005-1010. doi:10.1016/j.compstruct.2017.10.080.

[42] C. Yang, X. Tian, T. Liu, Y. Cao, D. Li, 3D printing for continuous fiber reinforced thermoplastic composites: mechanism and performance, Rapid Prototyp. J. 23 (2017) 209-215. doi:10.1108/RPJ-08-2015-0098.

[43] K. Oksman, M. Skrifvars, J.F. Selin, Natural fibres as reinforcement in polylactic acid (PLA) composites, Compos. Sci. Technol. 63 (2003) 1317-1324. doi:10.1016/S02663538(03)00103-9.

[44] H. Brooks, S. Molony, Design and evaluation of additively manufactured parts with three dimensional continuous fibre reinforcement, Mater. Des. 90 (2016) 276-283. doi:10.1016/j.matdes.2015.10.123.

[45] L.G. Blok, B.K.S. Woods, H. Yu, M.L. Longana, K.P. Potter, 3D Printed Composites Benchmarking the state of the art, in: 21st Int. Conf. Compos. Mater., 2017.

[46] R. Matsuzaki, M. Ueda, M. Namiki, T.K. Jeong, H. Asahara, K. Horiguchi, T. Nakamura, A. Todoroki, Y. Hirano, Three-dimensional printing of continuous-fiber composites by in-nozzle impregnation, Sci. Rep. 6 (2016) 1-7. doi:10.1038/srep23058.

[47] P. Zhuo, S. Li, I. Ashcroft, A. Jones, J. Pu, 3D Printing of Continuous Fibre Reinfroced Thermoplastic Composites, in: 21st Int. Conf. Compos. Mater., 2017.

[48] J. Justo, L. Távara, L. García-Guzmán, F. París, Characterization of 3D printed long fibre reinforced composites, Compos. Struct. 185 (2018) 537-548. doi:10.1016/j.compstruct.2017.11.052.

[49] F. Van Der Klift, Y. Koga, A. Todoroki, M. Ueda, Y. Hirano, R. Matsuzaki, 3D Printing of Continuous Carbon Fibre Reinforced Thermo-Plastic (CFRTP) Tensile Test Specimens, Open J. Compos. Mater. 06 (2016) 18-27. doi:10.4236/ojcm.2016.61003.

[50] F. Baumann, J. Scholz, J. Fleischer, Investigation of a New Approach for Additively Manufactured Continuous Fiber-reinforced Polymers, Procedia CIRP. 66 (2017) 323328. doi:10.1016/j.procir.2017.03.276.

[51] T. Hofstätter, D.B. Pedersen, G. Tosello, H.N. Hansen, State-of-the-art of fiberreinforced polymers in additive manufacturing technologies, J. Reinf. Plast. Compos. 36 (2017) 1061-1073. doi:10.1177/0731684417695648.

[52] D. Adams, C.J. Turner, An implicit slicing method for additive manufacturing processes, Virtual Phys. Prototyp. 13 (2018) 2-7. doi:10.1080/17452759.2017.1392684.

[53] F. Ning, W. Cong, Y. Hu, H. Wang, Additive manufacturing of carbon fiber-reinforced plastic composites using fused deposition modeling: Effects of process parameters on tensile properties, J. Compos. Mater. 51 (2017) 451-462. doi:10.1177/0021998316646169.

[54] A. Alafaghani, A. Qattawi, B. Alrawi, A. Guzman, Experimental Optimization of Fused Deposition Modelling Processing Parameters: A Design-for-Manufacturing Approach, Procedia Manuf. 10 (2017) 791-803. doi:10.1016/j.promfg.2017.07.079.

[55] H. Dou, Y. Cheng, W. Ye, D. Zhang, J. Li, Z. Miao, S. Rudykh, Effect of Process 
Parameters on Tensile Mechanical Properties of 3D Printing Continuous Carbon FiberReinforced PLA Composites, Materials (Basel). $13 \quad$ (2020). doi:doi:10.3390/ma13173850.

[56] B. Brenken, E. Barocio, A. Favaloro, V. Kunc, R.B. Pipes, Fused Filament Fabrication of Fiber-Reinforced Polymers: A Review, Addit. Manuf. 21 (2018) 1-16. doi:10.1016/j.addma.2018.01.002.

[57] H. Eiliat, J. Urbanic, Visualizing, analyzing, and managing voids in the material extrusion process, Int. J. Adv. Manuf. Technol. 96 (2018) 4095-4109. doi:https://doi.org/10.1007/s00170-018-1820-5.

[58] X. Wang, M. Jiang, Z. Zhou, J. Gou, D. Hui, 3D printing of polymer matrix composites: A review and prospective, Compos. Part B Eng. 110 (2017) 442-458. doi:10.1016/j.compositesb.2016.11.034.

[59] Z. Quan, A. Wu, M. Keefe, X. Qin, J. Yu, J. Suhr, J.H. Byun, B.S. Kim, T.W. Chou, Additive manufacturing of multi-directional preforms for composites: Opportunities and challenges, Mater. Today. 18 (2015) 503-512. doi:10.1016/j.mattod.2015.05.001.

[60] G.D. Goh, V. Dikshit, A.P. Nagalingam, G.L. Goh, S. Agarwala, S.L. Sing, J. Wei, W.Y. Yeong, Characterization of mechanical properties and fracture mode of additively manufactured carbon fiber and glass fiber reinforced thermoplastics, Mater. Des. 137 (2018) 79-89. doi:10.1016/j.matdes.2017.10.021.

[61] J. Plocher, A. Panesar, Review on design and structural optimisation in additive manufacturing: Towards next-generation lightweight structures, Mater. Des. 183 (2019) 108164. doi:10.1016/j.matdes.2019.108164.

[62] D. Ding, Z. Pan, D. Cuiuri, H. Li, S. van Duin, Advanced Design for Additive Manufacturing: 3D Slicing and 2D Path Planning, in: I. V Shishkovsky (Ed.), InTech, INTECH, 2016. doi:10.5772/63042.

[63] M.R. Dunlavey, Efficient polygon-filling algorithms for raster displays, ACM Trans. Graph. 2 (1983) 264-273. doi:10.1145/245.248.

[64] M. Wojcik, L. Koszalka, I. Pozniak-koszalka, A. Kasprzak, MZZ-GA Algorithm for Solving Path Optimization in 3D Printing, in: ICONS 2015 Tenth Int. Conf. Syst., Barcelona (Spain), 2015: pp. 30-35.

[65] S.C. Park, B.K. Choi, Tool-path planning for direction-parallel area milling, CAD Comput. Aided Des. 32 (2000) 17-25. doi:10.1016/S0010-4485(99)00080-9.

[66] V.T. Rajan, V. Srinivasan, K. a. Tarabanis, The optimal zigzag direction for filling a two-dimensional region, Rapid Prototyp. J. 7 (2001) 231-241. doi:10.1108/13552540110410431.

[67] P. Selvaraj, P. Radhakrishnan, Algorithm for pocket milling using zig-zag tool path, Def. Sci. J. 56 (2006) 117-127. doi:10.14429/dsj.56.1876.

[68] S. Dhanik, P. Xirouchakis, Contour parallel milling tool path generation for arbitrary pocket shape using a fast marching method, Int. J. Adv. Manuf. Technol. 50 (2010) 1101-1111. doi:10.1007/s00170-010-2580-z.

[69] Z. Lin, J. Fu, H. Shen, X. Yao, Smooth contour-parallel tool path generation for highspeed machining through a dual offset procedure, Int. J. Adv. Manuf. Technol. 81 (2015) 1233-1245. doi:10.1007/s00170-015-7275-z.

[70] Y. Yang, H.T. Loh, J.Y.H. Fuh, Y.G. Wang, Equidistant path generation for improving scanning efficiency in layered manufacturing, Rapid Prototyp. J. 8 (2002) 30-37. doi:10.1108/13552540210413284.

[71] F. Ren, Y. Sun, D. Guo, Combined reparameterization-based spiral toolpath generation for five-axis sculptured surface machining, Int. J. Adv. Manuf. Technol. 40 (2009) 760768. doi:10.1007/s00170-008-1385-9.

[72] E. Lee, Contour offset approach to spiral toolpath generation with constant scallop 
height, CAD Comput. Aided Des. 35 (2003) 511-518. doi:10.1016/S00104485(01)00185-3.

[73] B. Zhou, J. Zhao, L. Li, CNC double spiral tool-path generation based on parametric surface mapping, CAD Comput. Aided Des. 67-68 (2015) 87-106. doi:10.1016/j.cad.2015.06.005.

[74] I.T. Ozbolat, A.K.M.B. Khoda, Design of a New Parametric Path Plan for Additive Manufacturing of Hollow Porous Structures With Functionally Graded Materials, J. Comput. Inf. Sci. Eng. 14 (2014) 041005. doi:10.1115/1.4028418.

[75] G.Q. Jin, W.D. Li, L. Gao, K. Popplewell, A hybrid and adaptive tool-path generation approach of rapid prototyping and manufacturing for biomedical models, Comput. Ind. 64 (2013) 336-349. doi:10.1016/j.compind.2012.12.003.

[76] S. Lin, L. Xia, G. Ma, S. Zhou, Y. Min, A maze-like path generation scheme for fused deposition modeling, Int. J. Adv. Manuf. Technol. 104 (2019) 1509-1519. doi:https://doi.org/10.1007/s00170-019-03986-7.

[77] A. Papacharalampopoulos, H. Bikas, P. Stavropoulos, Path planning for the infill of 3D printed parts utilizing Hilbert curves, Procedia Manuf. 21 (2018) 757-764. doi:10.1016/j.promfg.2018.02.181.

[78] Y. Jin, Y. He, J. Du, A novel path planning methodology for extrusion-based additive manufacturing of thin-walled parts, Int. J. Comput. Integr. Manuf. 30 (2017) 1301-1315. doi:10.1080/0951192X.2017.1307526.

[79] J.C. Steuben, A.P. Iliopoulos, J.G. Michopoulos, Computer-Aided Design Implicit slicing for functionally tailored additive manufacturing, Comput. Des. 77 (2016) 107119. doi:10.1016/j.cad.2016.04.003.

[80] J.C. Steuben, A.P. Lliopoulos, J.G. Michopoulos, Towards Multiscale Topology Optimization for Additveley Manufactured Components Using Implicit Slicing, in: 2017 Int. Des. Eng. Tech. Conf. Comput. Inf. Eng. Conf., 2017: pp. 1-11.

[81] P. Lechowicz, L. Koszalka, I. Pozniak-koszalka, A. Kasprzak, Path Optimization in 3D Printer: Algorithms and Experimentation System, in: 4th Int. Symp. Comput. Bus. Intell., Olten (Switzerland), 2016: pp. 137-142.

[82] S. Patrick, A. Nycz, M. Noakes, Reinforcement Learning for Generating Toolpaths in Additive Manufacturing, in: Proc. 29th Annu. Int. Solid Free. Fabr. Symp., Austin (Texas), 2018: pp. 1612-1621.

[83] J. Wu, A. Clausen, O. Sigmund, Minimum compliance topology optimization of shellinfill composites for additive manufacturing, Comput. Methods Appl. Mech. Eng. 326 (2017) 358-375. doi:10.1016/j.cma.2017.08.018.

[84] P.J. Baikerikar, C.J. Turner, Comparison of as-built FEA simulations and experimental results for additively manufactured dogbone geometries, in: Proc. ASME 2017 Int. Des. Eng. Tech. Conf. Comput. Inf. Eng. Conf. IDETC/CIE, Cleveland (USA), 2017: pp. 114.

[85] D. Ding, Z. Pan, D. Cuiuri, H. Li, S. Van Duin, N. Larkin, Bead modelling and implementation of adaptive MAT path in wire and arc additive manufacturing, Robot. Comput. Integr. Manuf. 39 (2016) 32-42. doi:10.1016/j.rcim.2015.12.004.

[86] D. Ding, Z. Pan, D. Cuiuri, H. Li, A practical path planning methodology for wire and arc additive manufacturing of thin-walled structures, Robot. Comput. Integr. Manuf. 34 (2015) 8-19. doi:10.1016/j.rcim.2015.01.003.

[87] D. Ding, Z. Pan, D. Cuiuri, H. Li, N. Larkin, Adaptive path planning for wire-feed additive manufacturing using medial axis transformation, J. Clean. Prod. 133 (2016) 942-952. doi:10.1016/j.jclepro.2016.06.036.

[88] H. Prüß, T. Vietor, Design for Fiber-Reinforced Additive Manufacturing, J. Mech. Des. 137 (2015) 111409. doi:10.1115/1.4030993. 
[89] J.R.C. Dizon, A.H. Espera, Q. Chen, R.C. Advincula, Mechanical characterization of 3D-printed polymers, Addit. Manuf. $20 \quad$ (2018) 44-67. doi:10.1016/j.addma.2017.12.002.

[90] C. Casavola, A. Cazzato, V. Moramarco, C. Pappalettere, Orthotropic mechanical properties of fused deposition modelling parts described by classical laminate theory, Mater. Des. 90 (2016) 453-458. doi:10.1016/j.matdes.2015.11.009.

[91] C. Dapogny, R. Estevez, A. Faure, G. Michailidis, Shape and topology optimization considering anisotropic features induced by additive manufacturing processes, HAL Arch. (2018) 1-39. doi:hal01660850v3.

[92] N. Li, G. Link, T. Wang, V. Ramopoulos, D. Neumaier, J. Hofele, M. Walter, J. Jelonnek, Path-designed 3D printing for topological optimized continuous carbon fibre reinforced composite structures, Compos. Part B. $182 \quad$ (2020) 107612. doi:10.1016/j.compositesb.2019.107612.

[93] C.J. Brampton, K.C. Wu, H.A. Kim, New optimization method for steered fiber composites using the level set method, Struct. Multidiscip. Optim. 52 (2015) 493-505. doi:10.1007/s00158-015-1256-6.

[94] J. Liu, H. Yu, Concurrent deposition path planning and structural topology optimization for additive manufacturing, Rapid Prototyp. J. 23 (2017) 930-942. doi:10.1108/RPJ-052016-0087.

[95] T. Shafighfard, T.A. Cender, E. Demir, Additive manufacturing of compliance optimized variable stiffness composites through short fiber alignment along curvilinear paths, Addit. Manuf. 37 (2021) 101728. doi:10.1016/j.addma.2020.101728.

[96] Y. Chen, L. Ye, Topological design for 3D-printing of carbon fibre reinforced composite structural parts, Compos. Sci. Technol. $204 \quad$ (2021) 108644. doi:10.1016/j.compscitech.2020.108644.

[97] P. Gupta, B. Krishnamoorthy, G. Dreifus, Computer-Aided Design Continuous toolpath planning in a graphical framework for sparse infill additive manufacturing, Comput. Des. 127 (2020) 102880. doi:10.1016/j.cad.2020.102880.

[98] A. Spickenheuer, M. Schulz, K. Gliesche, G. Heinrich, Using tailored fibre placement technology for stress adapted design of composite structures, Plast. Rubber Compos. 37 (2008) 227-232. doi:10.1179/174328908X309448.

[99] M. Bruyneel, S. Zein, A modified Fast Marching Method for defining fiber placement trajectories over meshes, Comput. Struct. $125 \quad$ (2013) 45-52. doi:10.1016/j.compstruc.2013.04.015.

[100] Eiger/Software, Markforged, Inc. (2018). https://markforged.com/eiger/ (accessed August 28, 2018).

[101] 9T LABS - Product Red Series ${ }^{\mathrm{TM}}$, 9T Labs AG. (n.d.). https://www.9tlabs.com/product (accessed November 10, 2020).

[102] AURA - Slicing Software for Composite Printing, Anisoprint Sarl. (n.d.). https://anisoprint.com/aura/ (accessed November 10, 2020).

[103] D.H. Douglas, T.K. Peucker, Algorithms for the reduction of the number of points required to represent a digitized line or its caricature, Cartogr. Int. J. Geogr. Inf. Geovisualization. 10 (1973). doi:10.3138/FM57-6770-U75U-7727.

[104] W. Schwanghart, Line Simplification, MathWorks. (2020). https://www.mathworks.com/matlabcentral/fileexchange/21132-line-simplification (accessed June 15, 2020).

[105] O. Sigmund, A 99 line topology optimization code written in Matlab, Struct. Multidiscip. Optim. 21 (2001) 120-127. doi:10.1007/s001580050176.

[106] International ASTM. D5766/D5766M-11(2018) Standard Test Method for Open-Hole Tensile Strength of Polymer Matrix Composite. doi: 
https://doi.org/10.1520/D5766_D5766M-11R18, West Conshohocken, PA, 2018.

[107] ASTM International. D7264/D7264M-15 Standard Test Method for Flexural Properties of Polymer Matrix Composite Materials. doi: https://doi.org/10.1520/D7264_D7264M15, West Conshohocken, PA, 2015. doi:10.1520/D7264.

[108] Duet3d - Adavanced 3D Printing Electronics, (2020). https:/www.duet3d.com/ (accessed October 13, 2020).

[109] Marlin Firmware, 2020. (n.d.). https://marlinfw.org/ (accessed October 13, 2020).

[110] Y. Chen, Q. He, 3D-printed short carbon fibre reinforced perforated structures with negative Poisson's ratios : Mechanisms and design, Compos. Struct. 236 (2020) 111859. doi:10.1016/j.compstruct.2020.111859.

[111] K. Saeed, A. Mcilhagger, E. Harkin-jones, J. Kelly, E. Archer, Predication of the inplane mechanical properties of continuous carbon fi bre reinforced 3D printed polymer composites using classical laminated-plate theory, Compos. Struct. 259 (2021) 113226. doi:10.1016/j.compstruct.2020.113226.

[112] Moses, Matlab FileExchange - $\quad$ spider_plot.m, (2021). https://github.com/NewGuy012/spider_plot (accessed February 25, 2021). 